\title{
An Assessment of Pseudo-Operational Ground-Based Light Detection and Ranging Sensors to Determine the Boundary-Layer Structure in the Coastal Atmosphere
}

\author{
Conor Milroy, ${ }^{1}$ Giovanni Martucci, ${ }^{1}$ Simone Lolli, ${ }^{2,3}$ Sophie Loaec, ${ }^{2}$ Laurent Sauvage, \\ Irène Xueref-Remy, ${ }^{4}$ Jošt V. Lavrič, ${ }^{4,5}$ Philippe Ciais, ${ }^{4}$ Dietrich G. Feist, ${ }^{5}$ Gionata Biavati, ${ }^{5}$ \\ and Colin D. O'Dowd ${ }^{1}$ \\ ${ }^{1}$ School of Physics and Centre for Climate and Air Pollution Studies, Ryan Institute, National University of Ireland, Galway, Ireland \\ ${ }^{2}$ Leosphere, 76 rue Monceau, 75008 Paris, France \\ ${ }^{3}$ Laboratoire de Meteorologie Dynamique, Ecole Polytechnique (LMD), 91128 Palaiseau, France \\ ${ }^{4}$ Laboratoire des Sciences du Climat et de l'Environnement (LSCE) Unité Mixte IPSL-UVSQ-CNRS-CEA, Orme des Merisiers, \\ 91191 Gif-Sur-Yvette Cedex, France \\ ${ }^{5}$ Max Planck Institute of Biogeochemistry, Hans-Knöll-Straße 10, 07745 Jena, Germany
}

Correspondence should be addressed to Conor Milroy, pricer@eircom.net

and Giovanni Martucci, giovanni.martucci@nuigalway.ie

Received 14 December 2011; Revised 17 March 2012; Accepted 20 March 2012

Academic Editor: Ismail Gultepe

Copyright ( 92012 Conor Milroy et al. This is an open access article distributed under the Creative Commons Attribution License, which permits unrestricted use, distribution, and reproduction in any medium, provided the original work is properly cited.

Twenty-one cases of boundary-layer structure were retrieved by three co-located remote sensors, One LIDAR and two ceilometers at the coastal site of Mace Head, Ireland. Data were collected during the ICOS field campaign held at the GAW Atmospheric Station of Mace Head, Ireland, from 8th to 28th of June, 2009. The study is a two-step investigation of the BL structure based on (i) the intercomparison of the backscatter profiles from the three laser sensors, namely the Leosphere ALS300 LIDAR, the Vaisala CL31 ceilometer and the Jenoptik CHM15K ceilometer; (ii) and the comparison of the backscatter profiles with twenty-three radiosoundings performed during the period from the 8th to the 15th of June, 2009. The sensor-independent Temporal HeightTracking algorithm was applied to the backscatter profiles as retrieved by each instrument to determine the decoupled structure of the BL over Mace Head. The LIDAR and ceilometers-retrieved BL heights were compared to the radiosoundings temperature profiles. The comparison between the remote and the in-situ data proved the existence of the inherent link between temperature and aerosol backscatter profiles and opened at future studies focusing on the further assessment of LIDAR-ceilometer comparison.

\section{Introduction}

The planetary boundary layer (PBL) is the atmospheric region with the highest concentration of aerosols between the ground level and the free troposphere. White et al. [1] provides an aerosol-based definition of the PBL height as the top of the atmospheric region where the friction and the convection generated at the surface influences directly the turbulent mixing which determines the homogeneous distribution of the aerosols

The PBL is subject of study by both modellers and experimentalists using different approaches and definitions to characterize the structure of the boundary layer. A shared view within the scientific community is to identify the PBL as the region where turbulent mixing of gas and aerosol occurs [1-4]. High concentrations (higher than in the PBL) of aerosol can also be found in correspondence of elevated aerosol layers of volcanic or desert dust origin in the free troposphere and up to the lower stratosphere [5-10]. Atmospheric aerosols affect air quality and climate: in terms of air quality, aerosols influence human health, leading to increased mortality rates and respiratory pathologies [11]. The well-known, though not quantified yet, direct effect of aerosols on climate is responsible for the alteration of 
the radiative forcing during the last 100 years. Almost all anthropogenic and biogenic particles are created inside the PBL where they can stay for days. Aerosols can be dispersed out of the PBL during strong convection or temporary breaks of the capping temperature inversion [12, 13]. Aerosols can be transported to the ground by precipitation or by dry gravitational settling. Whilst the first process occurs on a time scale of minutes to hours, the second typically occurs on daily time scales, increasing with PBL height. Lifetime of pollutants within the PBL depends on both local and synoptic meteorological conditions and on the locally advected air mass. There are then two ways the aerosols can be generated at one site, either locally or advected with the air mass which, depending on its origin, characterizes the aerosols load [14]. The GAW atmospheric research station of Mace Head, Ireland, is located at the interface between the Northeast Atlantic and Europe, thus enabling sampling of both the cleanest air entering into Europe along with some of the most polluted air being exported out of Europe into the North Atlantic [14-17]. The presented study aims to provide quantitative information on the local boundarylayer (BL) height and structure retrievals by one lidar and two ceilometers installed at the Mace Head station during the ICOS scientific field campaign (8-28 June, 2009) and to contribute to the assessment of the ceilometers' performances as compared to lidars'. Uncertainties and limitations found in this and in other recent studies greatly assist in the synergetic use of existing ceilometer/lidar networks across Europe. Previous intercomparison studies reported the improved efficiency of ceilometers in the detection of the BL with respect to the lidar techniques [18-21]. The method based on local maxima of the radiosounding-retrieved potential temperature vertical gradient is a convenient and widely used technique for both daytime and nighttime determination of the BL structure [22-25].

There are currently two main European projects, that is, EG-CLIMET and ACTRIS, a ceilometer network established by the National Meteorological Office (DWD) in Germany and an establishing ceilometer network outlined and defined by the EG-CLIMET COST Action which are investing scientific expertise in developing and assessing European networks of ceilometers using recognized BL retrieval techniques.

\section{Dataset Selection within ICOS Campaign}

Data were selected during the period from the 8th to the 28th of June 2009, in the frame of the ICOS (Integrated Carbon Observation System) field campaign at Mace Head. The ICOS system is a new European research infrastructure for quantifying and understanding the greenhouse balance of the European continent and of adjacent regions (http://www.icos-infrastructure.eu/). During the preparatory phase from 2008 until 2011, the building of the central facilities is initiated, and the project is technically developed to the level of a demonstration year of full operation, but with a reduced number of observational sites. As part of the field campaign, the data from one lidar and two ceilometers have been used for BL monitoring and analysis: the Leosphere ALS300, the Jenoptik CHM15K, and Vaisala CL31, respectively. Within the operating vertical range of each instrument, the lidar and the ceilometers provided the backscatter profiles used to retrieve the BL structure. The Temporal Height-Tracking (THT) algorithm [4, 26, 27] has been applied to the three sensors' output data to retrieve the two-layer structure of the local BL. The two layers are defined as a lower, well-mixed surface layer and a decoupled layer occupying the region below the free troposphere, that is, the decoupled residual (nocturnal) or convective (diurnal) layer. Besides the instruments listed here, an experimental Jenoptik CHM 15k-x instrument also took part in the campaign. However, due to transport problems this instrument arrived late for the campaign. Most of the measurements were made during a bad-weather period in the second half of the campaign and could not be readily analyzed with the THT algorithm. The analysis of the CHM 15k-x data and its performance with respect to the CHM 15k model will be discussed in a separate study.

Twenty-five meteorological radiosondes (Vaisala RS92SGPD) were made available for the ICOS campaign to provide tropospheric in situ profiling above Mace Head. The daily timetable counted four ascents at 05:15, 11:15, 17:15, and 23:15 UTC. Total of 23 radiosoundings have been launched during the first week of the campaign, that is, $8-15$ June. An independent algorithm was developed to retrieve the inversions in the radiosoundings temperature profiles and to compare them to the lidar- and ceilometers-retrieved $\mathrm{BL}$ structure thus providing autonomous comparison of the two-layer structure of the BL.

\section{Site and Instrumentation}

3.1. The Site. Located on the west coast of Ireland $\left(53.20^{\circ} \mathrm{N}\right.$, $\left.9.54^{\circ} \mathrm{W}\right)$, the Atmospheric Research Station of Mace Head, Carna, County Galway is unique in Europe: its position offers westerly exposure to the North Atlantic Ocean through the clean sector $\left(190^{\circ}-300^{\circ} \mathrm{N}\right)$ and the opportunity to study atmospheric composition under Northern Hemispheric background conditions as well as European continental emissions when the winds favour transport from that region. The site is located in the path of the midlatitude cyclones which frequently traverse the North Atlantic. The station equipment was located $300 \mathrm{~m}$ from the shore line on a gently sloping hill (4 degrees incline).

3.2. Leosphere ALS300. The ALS300 uses a tripled pulse laser source Nd:YAG at $355 \mathrm{~nm}$ wavelength with an energy of $16 \mathrm{~mJ}$ per pulse at $20 \mathrm{~Hz}$ repetition rate. Both analogue and photon counting detection is available. The lidar system provides a real-time measurement, of backscattering and extinction coefficients, Aerosol Optical Depth, automatic detection of the planetary boundary layer height and clouds base and top from $75 \mathrm{~m}$ (200 m full overlap, Figure 1(a)) up to $20 \mathrm{~km}$, together with scanning capabilities and polarization channel with a raw resolution of $1.5 \mathrm{~m}$. The ALS300 retrieves aerosols extinction optical profiles using Klett 


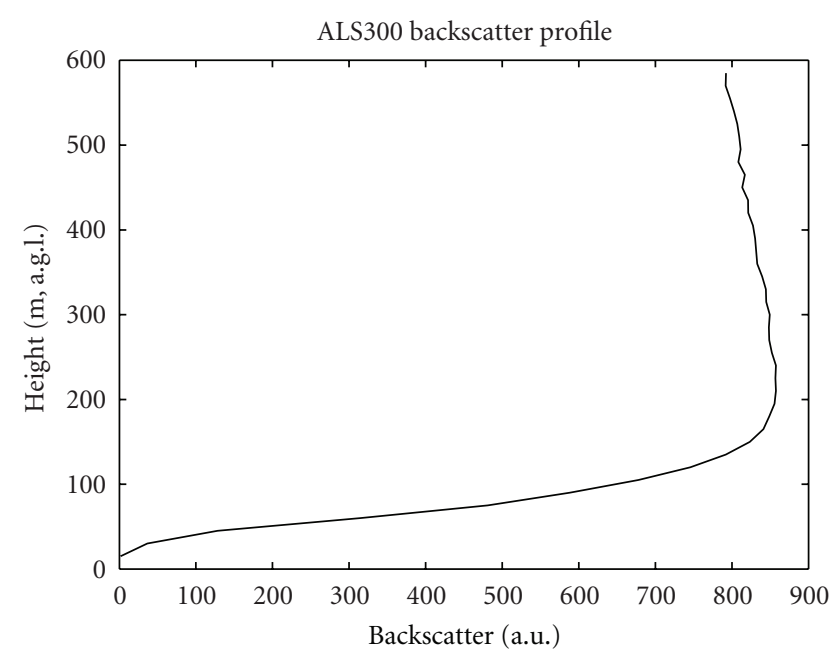

(a)

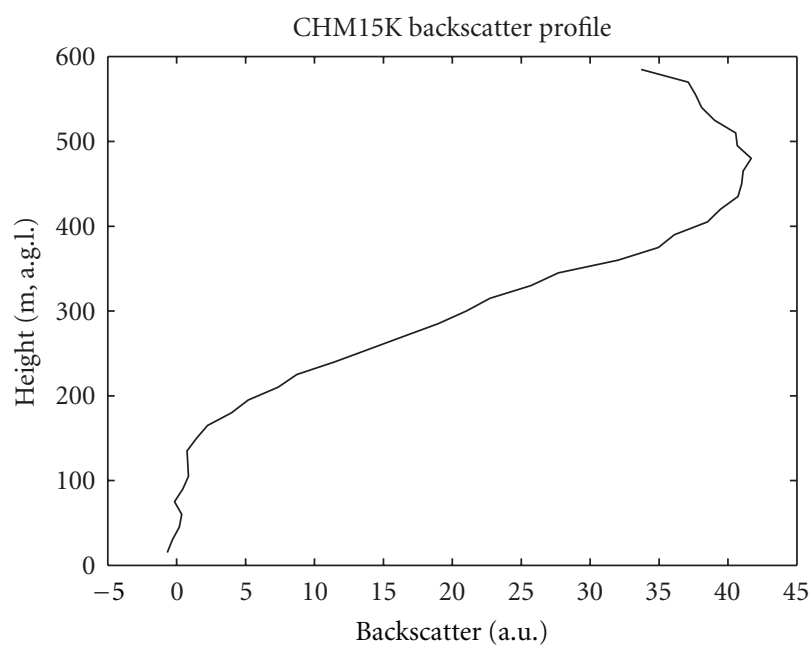

(b)

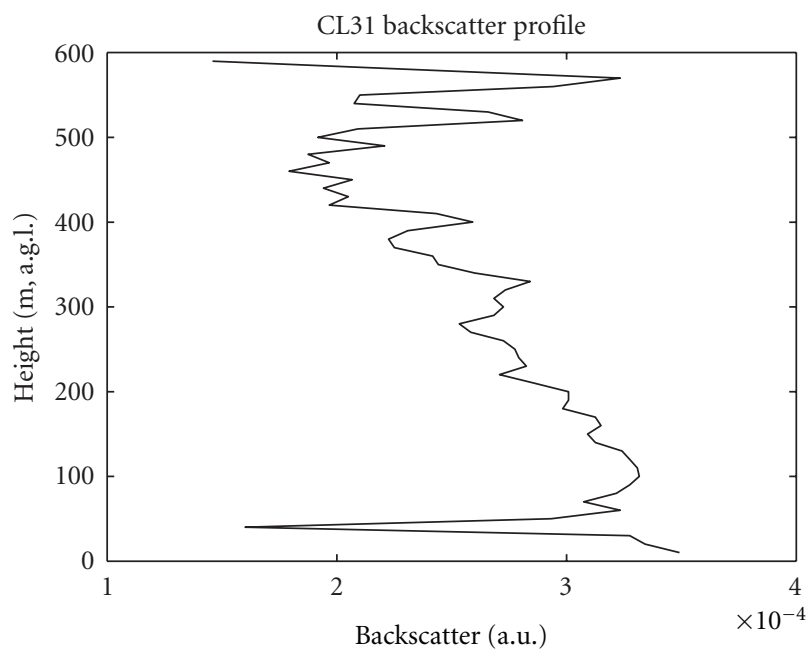

(c)

Figure 1: $0 \mathrm{~m}$ to $600 \mathrm{~m}$ height section of ALS300, CHM15K, and CL31's 10-minute average of backscatter profile. backward inversion algorithm [28]; the backscattering-toextinction ratio is assumed in the inversion procedure.

3.3. Jenoptik CHM15K. The CHM15K ceilometer [26, 29, 30] uses a laser source which is a diode-pumped Nd-YAG laser $(1064 \mathrm{~nm})$ yielding about $8 \mu \mathrm{J}$ per pulse at $5-7 \mathrm{KHz}$ repetition rate. It measures atmospheric target backscatter profiles over the nominal range $0.03-15 \mathrm{~km}$ with first overlap point at $30 \mathrm{~m}$ and 1500 full overlap (Figure 1(b)). In the operating range of 15 kilometres it can reliably detect lower cloud layers as well as cirrus clouds although the latter can be hidden in the noisy component of the signal at these high ranges. The highest vertical resolution at which the instrument can work is $15 \mathrm{~m}$ with measured full vertical profiles of aerosol backscatter and detected cloud height, boundary layer height, and visibility values. The measuring principle is lidar based with photon-counting detection system.

3.4. Vaisala CL31. The CL31 uses InGasAs diode emitting at $910 \mathrm{~nm}$ yielding about $1.2 \mu \mathrm{J}$ per pulse at the $8.192 \mathrm{KHz}$ repetition rate. The enhanced single lens technology applied to the CL31 ensures realistic data recording over the nominal range $0-7.5 \mathrm{~km}$ with first point of overlap at $0 \mathrm{~m}$ (full overlap nearly at the first range gate, [31]). The bottom panel of Figure 1 shows the first-bin full overlap of the CL31. Although the single lens technology is meant to provide reliability during precipitation, the receiving system becomes saturated very quickly during precipitation events as what happens with the other sensors.

\section{BL Dynamics}

Characteristic of this region and related to warm waters, the marine boundary layer is typically two layered with a surface mixed layer (SML) and a decoupled residual or convective layer (DRCL) above which is the free troposphere $[2,32]$. The site is exposed to both continental and marine air masses, with aerosol load changing accordingly to the air signature. Changes in air masses (temperature and aerosol load and type) directly affect the BL's depth and the aerosol concentration; BL is normally deeper during southern, moist periods and shallower when the air masses carry clean Arctic marine air [14]. Previous studies in which the CHM15K ceilometer, the RPG-HATPRO multichannel microwave profiler, and the MIRA36 $35 \mathrm{GHz}$ K-band Doppler cloud radar were used simultaneously showed that for extended periods of $\mathrm{BL}$ monitoring during different air masses the distance between SML and DRCL remains fairly constant $[14,33]$. The results showed that the BL decoupling over Mace Head is independent of the air mass characteristic. The next sections will present the relation between temperature and backscatter profiles to retrieve the BL decoupled structure; it is then important to understand how temperature and aerosols influence each others in the lower troposphere. As described in the study by Haeffelin and colleagues [4], when aerosols are uplifted after sunrise by convective mixing, they act as efficient tracers of the atmospheric portion 
over which the mixing occurs. During the day, the level at which air parcels become negatively buoyant corresponds to a main temperature inversion. It often happens that the convection erodes the temperature inversion allowing the buoyant air parcel to be lifted further up. When turbulence weakens in the afternoon, due to the decreasing sensible heat flux, the temperature inversion builds up again and the depth over which mixing occurs becomes shallower, but the aerosols can remain aloft, without evident subsidence. In these afternoons and after-sunset conditions, the strongest aerosol gradient corresponds to a residual aerosol layer aloft the actual SML. The residual layer height corresponds then to a higher (in altitude) temperature inversion. Departure from these dynamics can be found when the residual layer does not completely disappear during daytime and the BL structure remains decoupled also during central hours. Another example of no matching between aerosol and temperature gradients may occur when a temperature inversion forms by radiative cooling of the underlying layer in the already developed BL; aerosols would then be homogeneously distributed below and above the inversion and no gradient would be found in the lidar data.

\section{Theory of the Method}

The power of the lidar signal, $P(h)$, backscattered by an atmospheric layer of thickness $\Delta h$ (range gate) centred at altitude $h$ can be expressed in the form [34]

$$
P(h)=P_{L} K O(h) \frac{A}{h^{2}} \Delta h \beta(h) T^{2}(h)+B
$$

$P_{L}$ is the emitted optical power, $K$ is the overall optical efficiency of the instrument, $O(h)$ is the overlap function, $A$ is the receiver area, and $T(h)=\exp \left\{-2 \int_{0}^{h} \alpha\left(h^{\prime}\right) d h^{\prime}\right\}$ is the round-trip transmission factor. Variables $\alpha$ and $\beta$ are, respectively, the extinction (in $\left[\mathrm{m}^{-1}\right]$ ) and the volume backscattering (in $\left[\mathrm{sr}^{-1} \mathrm{~m}^{-1}\right]$ ) coefficients. The last term $B$ is the sum of the electronic and optical background noise. The coefficients $\alpha$ and $\beta$ can be written as the combination of their aerosol and molecular components, that is, $\alpha=\alpha_{\mathrm{aer}}+\alpha_{\mathrm{mol}}$ and $\beta=\beta_{\mathrm{aer}}+\beta_{\mathrm{mol}}$. For the utilized wavelengths $(355 \mathrm{~nm}, 910 \mathrm{~nm}$, and $1064 \mathrm{~nm})$ the relation $\alpha_{\text {aer }}, \beta_{\text {aer }} \gg \alpha_{\text {mol }}, \beta_{\text {mol }}$ can be applied [21]. This assumption applies also to the gradient of the received power since the vertical changes in aerosol/hydrometeor concentration dominate the received signal at both long $(\lambda \approx 1 \mu \mathrm{m})$ and short wavelengths $(\lambda \approx 0.35 \mu \mathrm{m})$. The extinction and the backscatter coefficients can then be written as $\alpha \approx \alpha_{\text {aer }}$ and $\beta \approx \beta_{\text {aer }}$, respectively.

The attenuated atmospheric volume backscatter coefficient $\left(\beta^{\text {att }}\right)$ is computed as

$$
\beta^{\text {att }}(h)=\frac{[P(h)-B] h^{2}}{P_{L} K A \Delta h} .
$$

The vertical gradient applies to the natural logarithm of $\beta^{\text {att }}$. For a time series of $N$ profiles the $i$ th gradient profile has the expression

$$
G_{i}(h)=\frac{d}{d h} \log \left(\beta_{i}^{\text {att }}(h)\right)=\frac{d}{d h} \log \left(\beta_{i}(h)\right)-2 \alpha_{i}(h) .
$$

The index $i$ goes from 1 to the end of the dataset and $N$ depends on the dataset duration and the sampling rate (5 minutes for this study).

Both the backscatter and gradient profiles from the three sensors are used as input data for the THT algorithm $[26,27]$ running with 5-minute and 30-meter temporal and vertical resolution, respectively. The THT algorithm is sensor independent and is based on the information of the mutual positions of the local minima along $\beta^{\text {att }}$ and $G$ vertical profiles. The algorithm calculates the averaged $\bar{G}$ and $\overline{\beta^{\text {att }}}$ profiles from the $G_{i}$ and $\beta_{i}^{\text {att }}$ profiles over 10 minutes (i.e., over 2 profiles). The mean value between the heights of the two minima is a reference height, $h_{\text {ref }}$, used to "track" the successive BL height determinations at each $i$-step (new $h_{\text {ref }}$ heights are calculated every 10 minutes and used to determine the successive BL heights). The algorithm is robust under different meteorological conditions: using $h_{\text {ref }}$ as a tracking tool it allows including also short periods of precipitation and filtering out unrealistic peaks located too distant from the previous retrieval. The algorithm's parameters can be adjusted on a case-by-case basis with the possibility to adjust the retrieval scheme to more complex BL structure, like shallow SML and DRCL or significant variability over short time periods (high-frequency SML/DRCL temporal variation). The possibility to adjust the $h_{\text {ref }}$-centred vertical window allows the algorithm to minimize the error in the high-frequency scenarios. The 10-minute averaged reference backscatter profile has a reduced number of false peaks and higher signal-to-noise ratio (SNR). Other studies have shown techniques based on gradients in the lidar/ceilometer backscatter profiles and able to provide the mixing heights. The derivative of the backscatter profile is a well-established way to determine the mixing layer height $[21,25,35,36]$. The relative and absolute variability (variance) of the backscatter profile at fixed altitudes can be used as a proxy to detect the interface between two aerosol layers; examples of the variance technique can be found in Hennemuth and Lammert, 2006 [37]; Hooper and Eloranta, 1986 [38]; Menut et al., 1999 [36]; Martucci et al., 2007 [25]. Meteorological conditions causing low SNR (e.g., clouds, fog, and precipitation) can prove challenging when trying to assign a gradient to the mixing height. For that reason, other studies focused on ideal backscatter profiles $[39,40]$ as a benchmark to detect major gradients in correspondence to aerosol layers even in low SNR conditions.

Radiosounding-retrieved temperature profiles and their gradients are processed in order to return two inversions that represent the top of the SML and the DRCL. In order to compare the backscatter THT-retrieved and the radiosounding-retrieved depths of the SML and the DRCL we used the radiosoundings as an independent source of reference heights for the decoupled structure of the BL. No a priori assumptions have been made on the correctness of 
TABLE 1: Mean statistical parameters of the ALS300-CHM15K-CL31 intercomparison. For each $X$ versus $Y$ comparison, $R$ is the correlation coefficient, bias $=$ abs $(Y-X)$, Sigma $=$ std $(Y-X)$, and consistency is percentage of $X$ versus $Y$ detection closer than $200 \mathrm{~m}$, that is, abs $(Y-X) \leq 200 \mathrm{~m}$.

\begin{tabular}{|c|c|c|c|c|c|}
\hline Comparison (SML) & $R$ & Bias (m a.g.l.) & Sigma (m a.g.l.) & Consistency (\%) & No. of cases \\
\hline ALS300 versus CHM15K & 0.88 & 95.0 & 135.5 & 86.5 & 17 \\
\hline ALS300 versus CL31 & 0.76 & 156.1 & 189.0 & 71.0 & 15 \\
\hline CHM15K versus CL31 & 0.82 & 110.4 & 144.9 & 77.4 & 14 \\
\hline Comparison (DRCL) & $R$ & Bias (m a.g.l.) & Sigma (m a.g.l.) & Consistency $(\%)$ & \\
\hline ALS300 versus CHM15K & 0.83 & 131.1 & 179.4 & 77.2 & 17 \\
\hline ALS300 versus CL31 & 0.73 & 180.4 & 217.8 & 67.1 & 14 \\
\hline CHM15K versus CL31 & 0.71 & 166.9 & 207.4 & 69.0 & 14 \\
\hline
\end{tabular}

any amongst the lidar's and the ceilometers' THT retrievals when they are compared to the radiosoundings. The THT is indeed regarded and intended as neutral method to retrieve the decoupled structure of the BL above Mace Head.

\section{Results}

6.1. Lidar-Ceilometers Intercomparison. Vertical backscatter profiles from ceilometers and lidar have been processed by the THT to retrieve the two-layered structure of the BL. Figures 2 and 3 show examples of the time-height crosssection of the atmospheric-attenuated backscatter retrieved by the ALS300 (top), CHM15K (middle), and CL31 (bottom) in the time interval between 00:00 to 24:00 UTC on the 15th and 20th of June 2009, respectively. White circles and triangles represent the SML and DRCL heights, respectively. The two cases in the figures show a cloud-free and a cloudy BL daily development on the 15th and 20th of June 2009, respectively. Both the SML and DRCL on the 15th of June show moderate variability especially during the second part of the day, from 11:00 to 20:00 UTC. The SML variability on the 15th was higher compared to the 20th mainly because of the clear sky conditions that enhanced the convection in the lower layer. Similarly, the DRCL on the 15th had larger height fluctuations (top and middle panel) probably due to the formation and breakdown of thermals, transporting aerosols in updrafts and downdrafts at the top of the BL.

On the 20th of June, precipitation occurred in two short events at the beginning and at the end of the day; a thin deck of stratus cloud topping the SML formed since the early hours ( 02:30 UTC) remaining between $1000 \mathrm{~m}$ and $500 \mathrm{~m}$ until the afternoon (16:00 UTC) with only one short break in the cloud cover before noon. The detected BL presented a stratiform-driven structure with slowly changing SML height and a hardly detectable DRCL. The DRCL was not detected by the CL31 (bottom panel) due to the almost complete signal attenuation through the cloud layer. Conversely, the ALS300 could penetrate the cloud layer using larger power pulse and detect the above DRCL. In the middle panel, the CHM15K-retrieved DRCL closely matches the ALS300 detections.

In addition to the two cases shown in Figures 2 and 3 other cases have been selected to intercompare the ALS300-, the CHM15K-, and the CL31-retrieved BL structures profile by profile. The case selection was based on the following criteria: no or negligible precipitation occurring during the measurements; no or negligible fog causing the laser to be fully attenuated before reaching the actual BL height; the sensors operated with no technical difficulties; time of measurements is synchronized for all sensors. Table 1 summarizes the mean statistical properties of the intercomparison from the 8th of June 2009 to the 28th of June 2009 for the SML and the DRCL. For each $Y$ versus $X$ comparison (where $Y$ and $X$ refer each to a different sensor) the mean statistical variables are the correlation coefficient, $R$; the bias, that is, the mean absolute value of the difference between $Y$ and $X$ detections; sigma, that is, the standard deviation of the $Y$-X differences; the consistency, that is, the percentage of $X$ and $Y$ detections closer than $200 \mathrm{~m}$, that is, abs $(Y-X) \leq$ $200 \mathrm{~m}$.

Figures 4 and 5 show the linear correlations of the three-instrument intercomparison for the SML and DRCL detections on the 15th and 20th of June. The error bars in Figures 4 and 5 are the standard deviations $\sigma_{\text {THT }}$ representing the variability of contiguous BL heights retrievals over a fixed interval of time (see [27], for complete description of the error calculation). The DRCL detections are shown only for the 15th of June due to insufficient number of DRCL detections by the CL31 on the 20th of June. The different meteorological conditions on the 15th and the 20th corresponded to different performances of the lidar and the two ceilometers: the missing DRCL retrieval on the 20th is caused by both the presence of the cloud deck and the lower pulse power of the CL31 compared to the other two devices. For the SML, higher correlations are obtained for the case where the SML matches the cloud deck. The strong echo from the cloud is detected unambiguously by the three sensors and the transition between the SML to the DRCL is well defined. The presence of a strong gradient reduces significantly the THT uncertainty in assigning the SML height. The DRCL's best match on the 15th of June is between the ALS300 and the CHM15K; this is more generally confirmed by the statistics reported in Table 1: for the ALS300-CHM15K comparison the correlation coefficients $R$ at the SML and DRCL levels are 0.88 and 0.83 , respectively, with the most consistent retrievals amongst the three intercomparisons $(86.5 \%$ and $77.2 \%$ for SML and DRCL, resp.). 


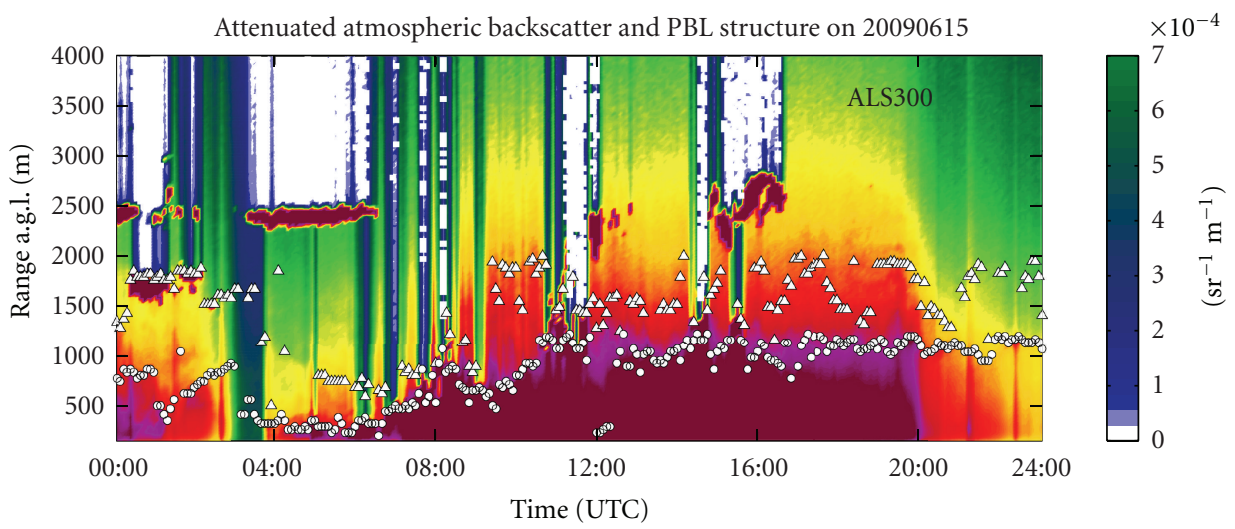

(a)

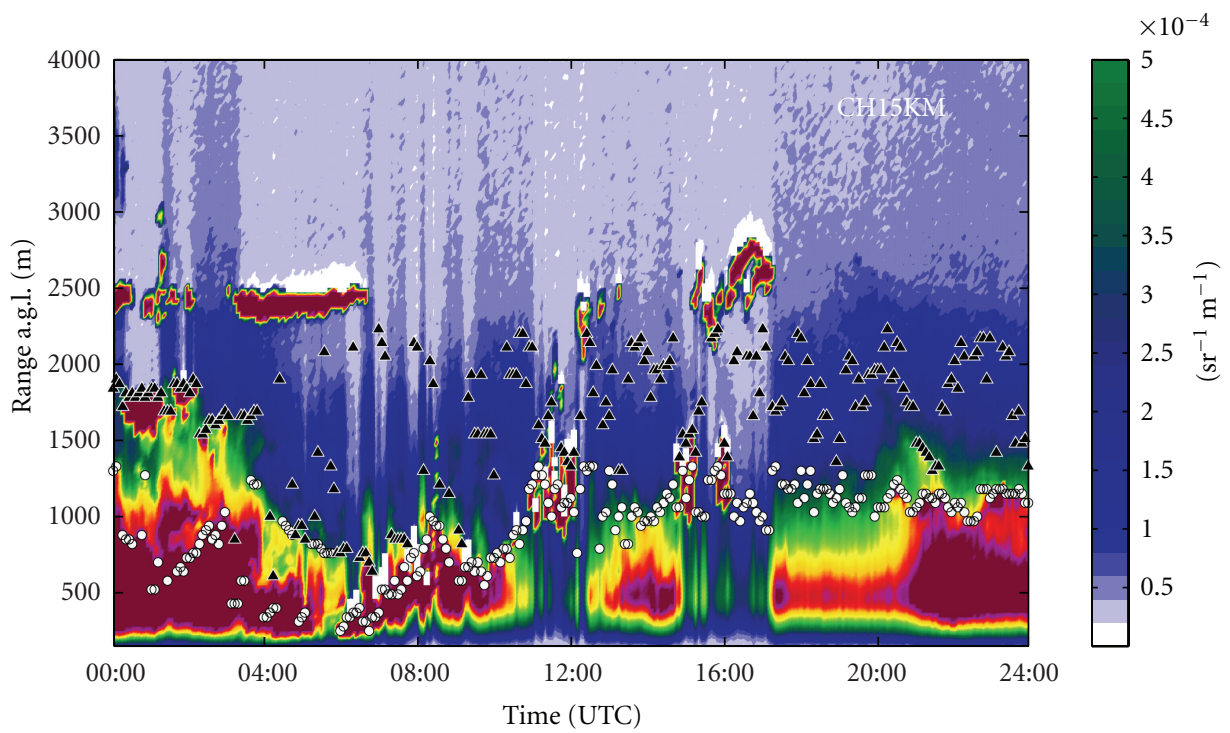

(b)

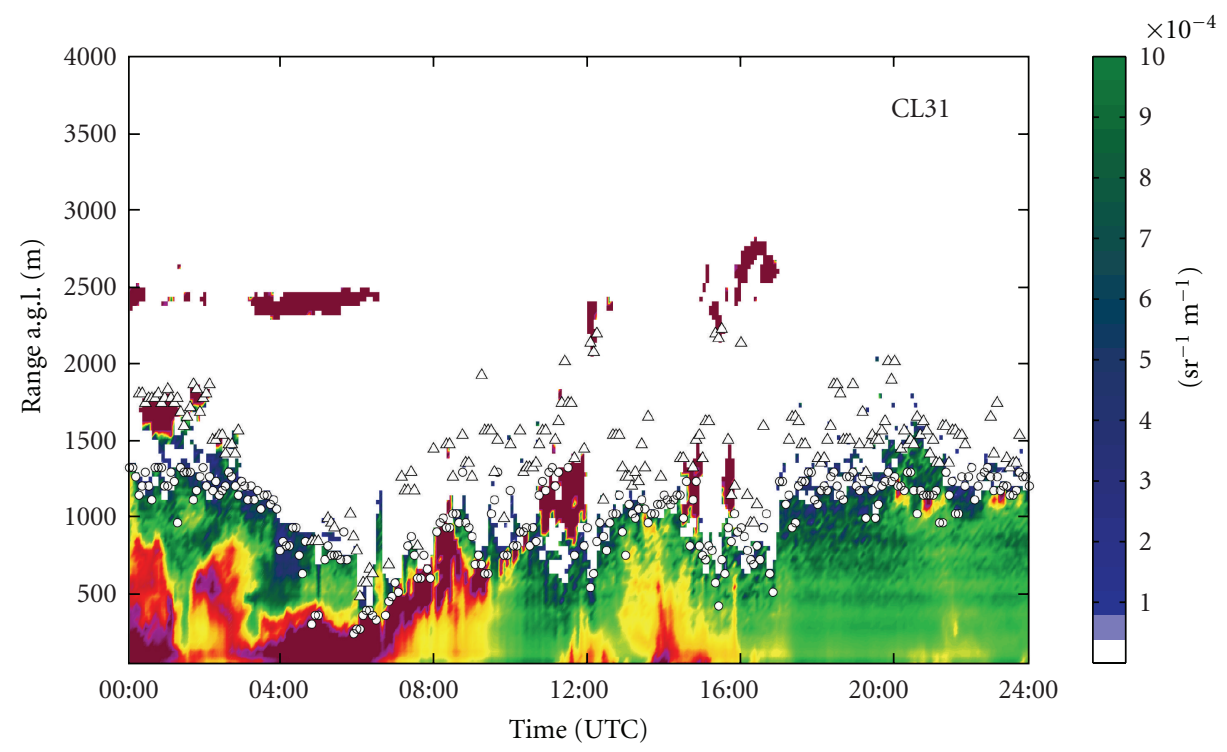

(c)

Figure 2: Time-height cross-sections of the atmospheric attenuated backscatter on the 15th of June 2009. 


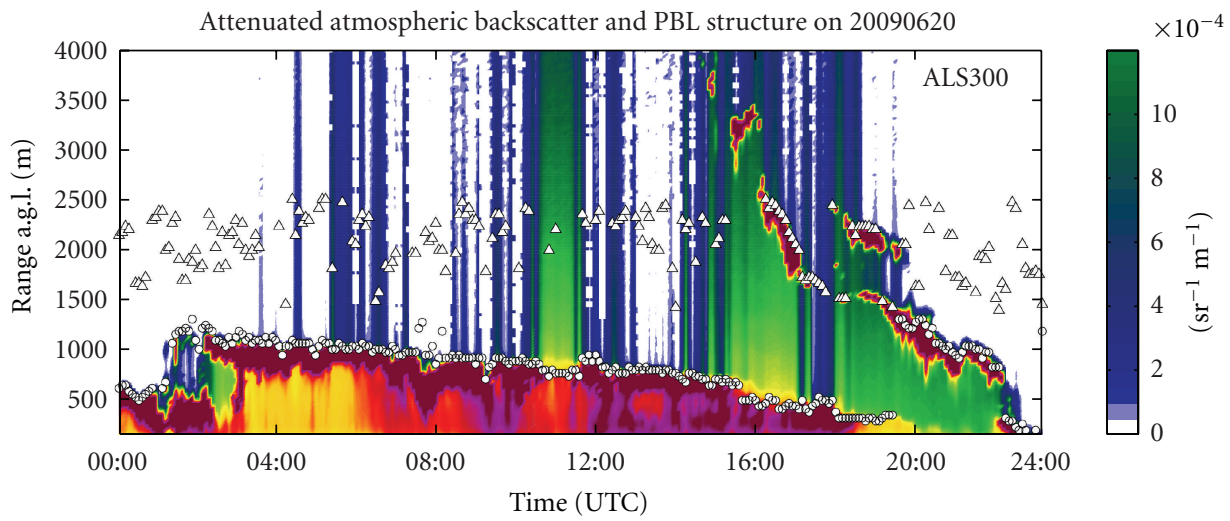

(a)

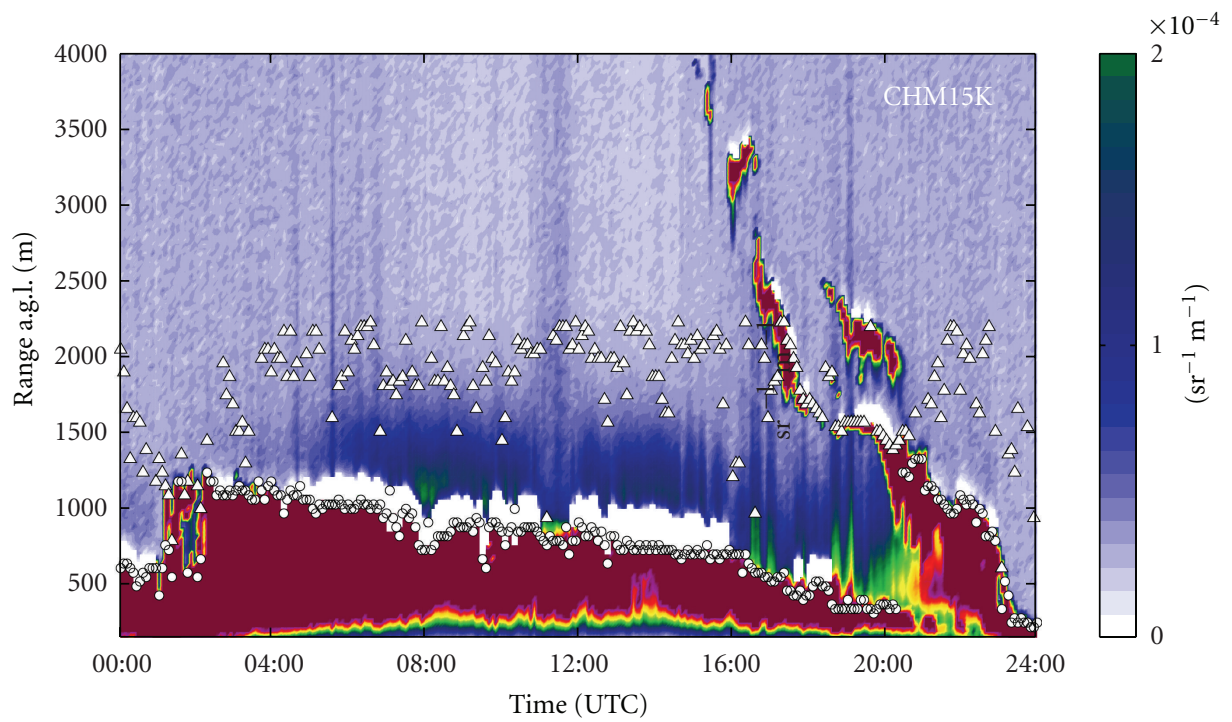

(b)

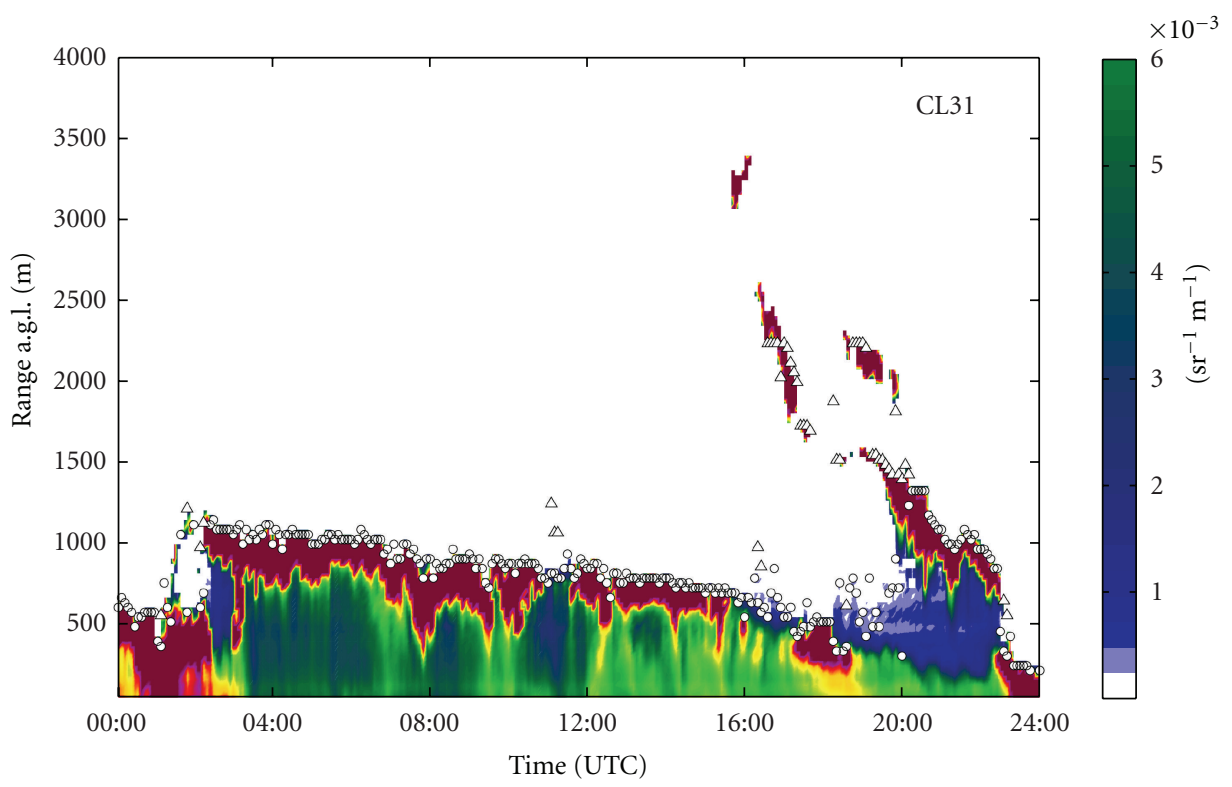

(c)

FIgURE 3: Time-height cross sections of the atmospheric attenuated backscatter for the 20th of June 2009. 

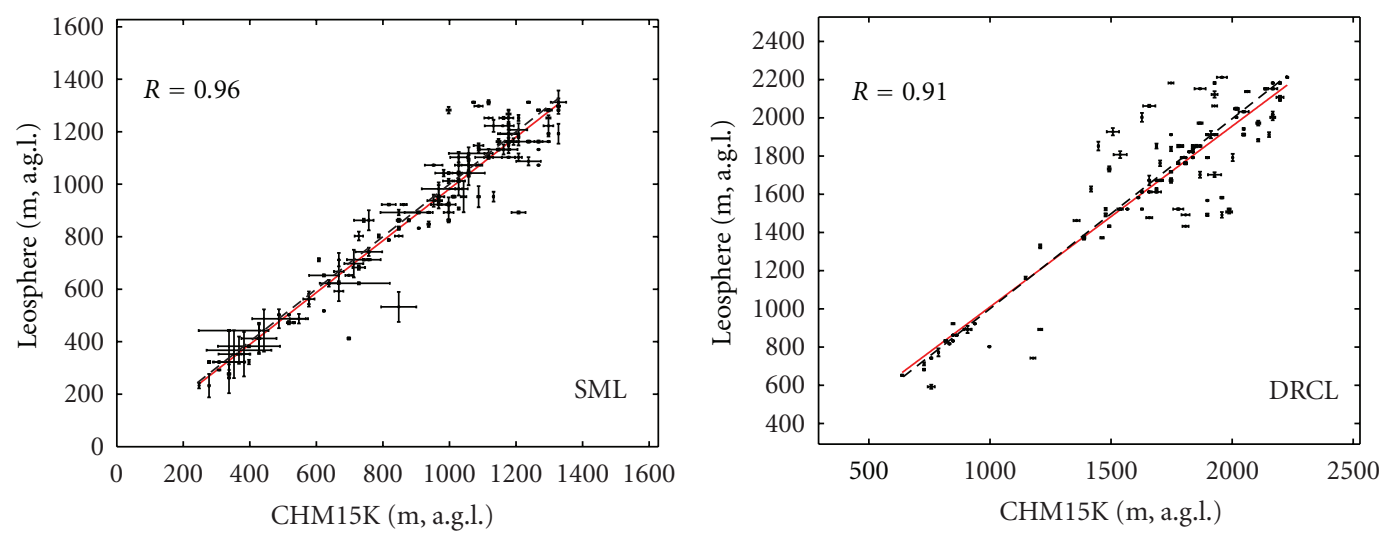

- CHM15K versus Leospher

- $Y=0.988^{*} X+-5.194$

-- $1: 1$ line

(a)

CHM15K versus Leosphere
$-\quad Y=0.946^{*} X+63.734$
$-\_-1: 1$ line

(b)

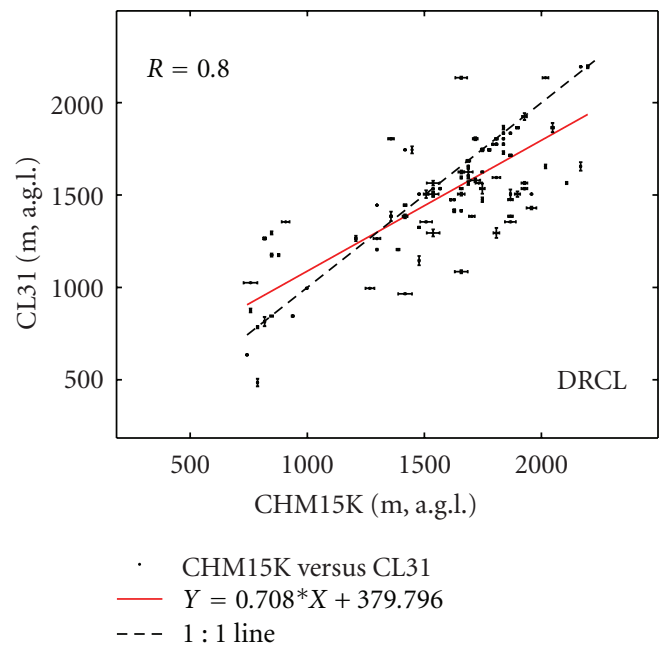

(d)

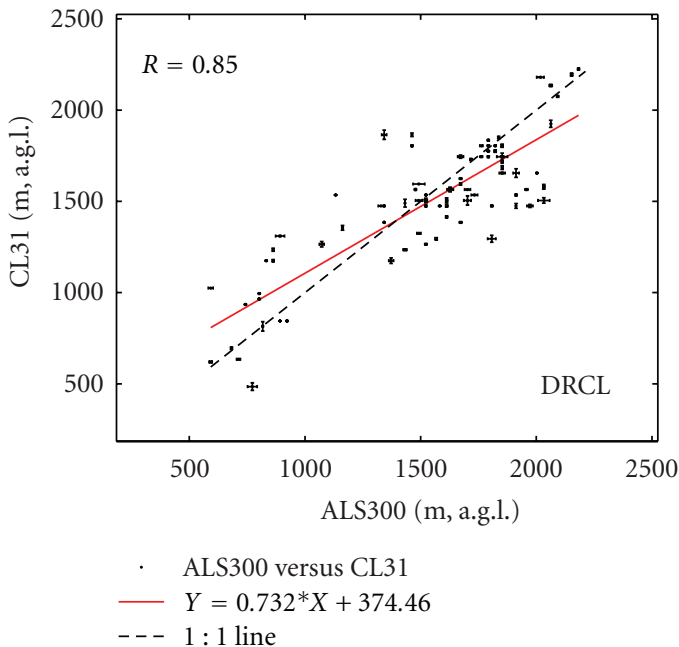

(f)

FIGURE 4: Linear correlation of SML and DRCL detections on the 15th of June, 2009. (a, b) show the ALS300-CHM15K comparison; (c, d) show CL31-CHM15K; (e, f) show CL31-ALS300. A filter has been applied for outliers $>2 \sigma_{\text {stdv }}$. Error bars have amplitude $2 \sigma_{\mathrm{THT}}$. 


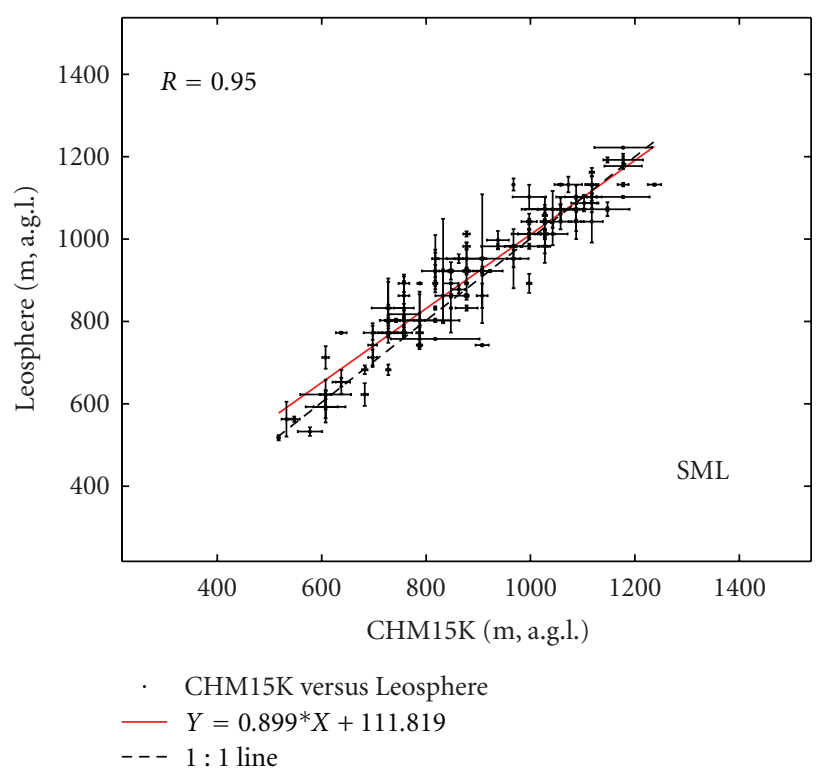

(a)

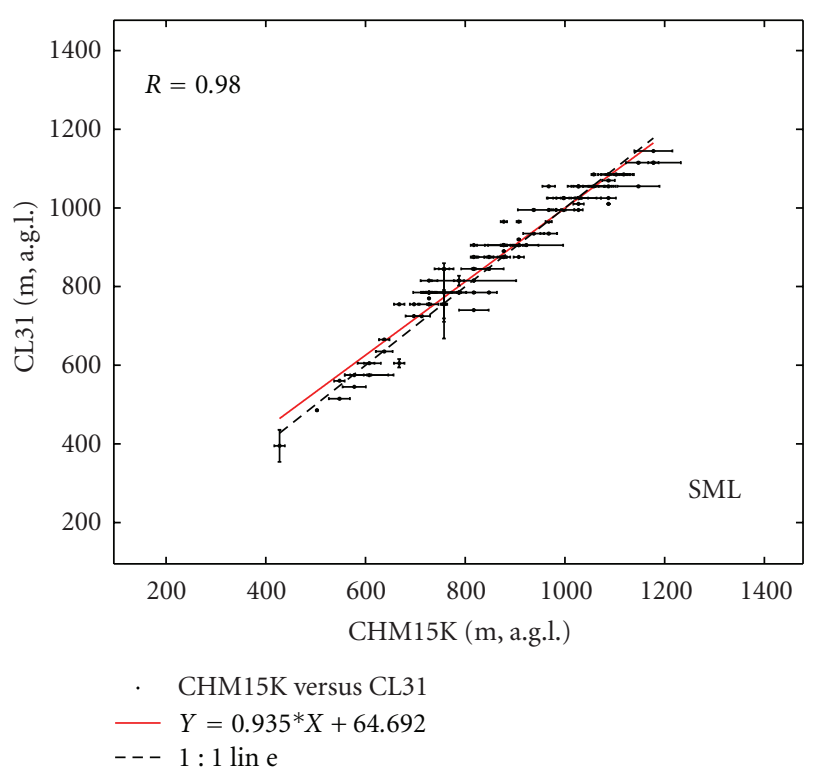

(b)

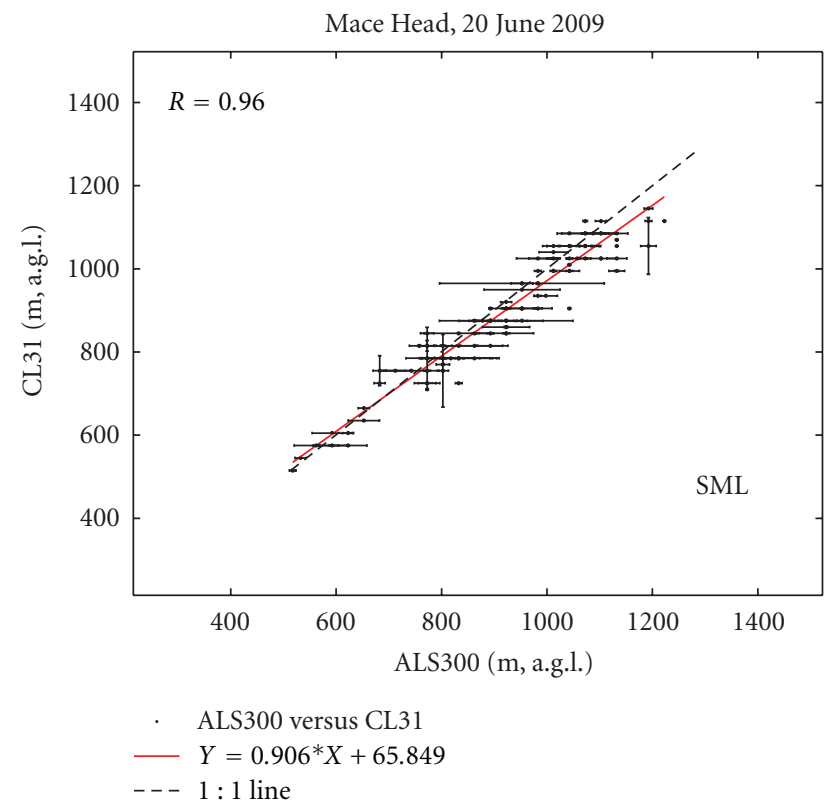

(c)

FIgURE 5: Linear correlations of SML detections on the 20th June 2009. (a) shows the comparison ALS300-CHM15K; (b) shows CL31CHM15K; (c) shows CL31-ALS300. A filter has been applied for outliers $>2 \sigma_{\text {stdv }}$. Error bars have amplitude $2 \sigma_{\text {THT }}$.

6.2. In Situ versus Remote Sensing Measurements. The THTprocessed backscatter profiles have been compared to the radiosoundings temperature data; Table 2 details the dataset used for the comparisons. The daily timetable counted four ascents at $05: 15,11: 15,17: 15$, and 23:15 UTC. Maxima in the vertical gradient of the radiosoundings temperature profile were used to determine the SML and the DRCL layers. The temperature-retrieved SML and DRCL were then compared to the different sensors' retrievals [25, 41]. Each radiosounding (RS) datum in Figures 6-8 corresponds to an average ascent duration of 10 minutes to reach the height of
$2000 \mathrm{~m}$. The ascent's duration determines also the time of average of the backscatter profile to be compared with the RS temperature vertical profile. Over all the collected cases, the mean calculated distance between the geographical position of the radiosoundings launch site and that of the radiosonde at the height of $2000 \mathrm{~m}$ was $4350 \mathrm{~m}$ with a standard deviation of $2760 \mathrm{~m}$. The mean direction of the displacement was from the West to the East, heading inland. Due to the homogeneous surface conditions (flat land, no vegetation, unvaried Albedo) $10000 \mathrm{~m}$ inland from the shoreline, a mismatch of BL heights between in situ and remote sensing 
measurements would be minimal and then not considered for this analysis.

Lidar and ceilometers data have not been used in three cases due to rain occurring during the radiosounding ascents. CHM15K data were not available on the 9th; data from the CL31 and ALS300 recorded on the 9th were not used then for the correlations (data from the 9th retrieved by the CL31 and ALS300 will be discussed separately in Section 6.3). Due to the limited number of available data points for the comparison, the obtained correlation coefficients $R$ are highly sensitive to the single datum; since the comparisons depend on a number of variables including the meteorological conditions (cloud cover, fog, and precipitation) and the aerosol load (optical thickness), an accurate analysis of all cases is performed in order to interpret correctly the obtained correlations.

Table 3 summarizes the statistical properties of the comparisons from the 9th of June 2009 to the 15th of June 2009 at the SML and DRCL levels. As for Table 1, the statistics is described by bias, sigma, and consistency of each instrument-RS comparison at the SML and DRCL levels. As expected, large gradients (inversions) in the backscatter (temperature) profiles led too well-defined SML and DRCL and higher $R$-values. Conversely, conditions with multiple gradients (inversions) and fast-fluctuating SML and DRCL determined low $R$-values.

6.2.1. ALS300 versus RS. Figure 6 shows the linear correlations between the ALS300 and the RS retrievals of the SML and DRCL detections. The ALS300-retrieved SML values distribute closely around the $1: 1$ line with $R=0.911$. The CHM15K data have slightly larger spread leading to $R=$ 0.882 and 0.811 at the SML and DRCL, respectively; the CL31 has $R=0.744$ and 0.605 at the SML and DRCL, respectively. The larger-than-one SNR within the BL allows to use the ALS300 backscatter profiles to detect fine aerosol layers within the BL allowing the unambiguous separation of gradients along the backscatter profiles. Albeit, the high resolution and SNR can become counterproductive when using a gradient-based algorithm such as THT: the high number of aerosol layers (and then gradients) within the SML or DRCL can lead to increased uncertainty when comparing the SML or the DRCL to the single RS inversions. The fact that the DRCL retrievals have comparable or slightly higher correlation coefficient $(0.922)$ with respect to the SML's supports the hypothesis that, whilst the interface with the free troposphere is explicitly detected, the THT suffers from significant uncertainty when dealing with multiple internal layers as it happens at the SML level. The number of data points is 16 for the SML and 13 for the DRCL; the statistical parameters reported in Table 3 show that the ALS300 retrievals of the SML and the DRCL are more consistent with $75 \%$ and $61.5 \%$ of retrievals closer than $200 \mathrm{~m}$ to the RS temperature inversions, respectively. The most consistent ALS300-RS SML detection was $27.5 \mathrm{~m}$ which occurred on the 15th of June at 05:05 UTC; the $200 \mathrm{~m}$ full overlap allowed the ALS300 to pick up the low-level inversion which delimited the upper boundary of the developing SML.
TABLE 2: List of backscatter data availability during the RS ascents.

\begin{tabular}{lccc}
\hline RS [dd mm yyyy, UTC] & CHM15K & CL31 & ALS300 \\
\hline 09 Jun 2009 05:16 & No data & $\checkmark$ & $\checkmark$ \\
09 Jun 2009 11:40 & No data & $\checkmark$ & $\checkmark$ \\
09 Jun 2009 23:00 & No data & $\checkmark$ & $\checkmark$ \\
10 Jun 2009 05:30 & rain & rain & rain \\
10 Jun 2009 11:15 & $\checkmark$ & No data & $\checkmark$ \\
10 Jun 2009 17:00 & $\checkmark$ & No data & $\checkmark$ \\
10 Jun 2009 23:15 & $\checkmark$ & No data & $\checkmark$ \\
11 Jun 2009 05:00 & $\checkmark$ & No data & $\checkmark$ \\
11 Jun 2009 11:15 & $\checkmark$ & No data & $\checkmark$ \\
11 Jun 2009 17:15 & $\checkmark$ & No data & $\checkmark$ \\
11 Jun 2009 23:00 & rain & rain & rain \\
12 Jun 2009 05:30 & rain & rain & rain \\
12 Jun 2009 11:15 & $\checkmark$ & $\checkmark$ & $\checkmark$ \\
12 Jun 2009 17:15 & $\checkmark$ & $\checkmark$ & $\checkmark$ \\
12 Jun 2009 23:15 & $\checkmark$ & $\checkmark$ & $\checkmark$ \\
13 Jun 2009 06:05 & $\checkmark$ & $\checkmark$ & $\checkmark$ \\
13 Jun 2009 17:35 & $\checkmark$ & $\checkmark$ & $\checkmark$ \\
13 Jun 2009 23:05 & $\checkmark$ & $\checkmark$ & $\checkmark$ \\
14 Jun 2009 05:05 & $\checkmark$ & $\checkmark$ & $\checkmark$ \\
14 Jun 2009 11:00 & $\checkmark$ & $\checkmark$ & $\checkmark$ \\
14 Jun 2009 17:05 & $\checkmark$ & $\checkmark$ & $\checkmark$ \\
14 Jun 2009 23:05 & $\checkmark$ & $\checkmark$ & $\checkmark$ \\
15 Jun 2009 05:05 & $\checkmark$ & $\checkmark$ & $\checkmark$ \\
\hline
\end{tabular}

The RS first temperature inversion was detected at $340 \mathrm{~m}$ whereas the THT-retrieved SML height from the ALS300 was $312.5 \mathrm{~m}$. The less consistent ALS300-RS SML retrieval was $437.5 \mathrm{~m}$, which occurred on the 14th of June at 05:05 UTC (SML and DRCL at $1090 \mathrm{~m}$ and $2378 \mathrm{~m}$ ). A large bias occurred throughout the entire day, mainly because of the marked convective conditions. The DRCL comparison counts 13 samples, the most consistent ALS300-RS DRCL detection being as low as $6.5 \mathrm{~m}$ which occurred on the 13th of June at 06:05 UTC (SML and DRCL at $936 \mathrm{~m}$ and $2420 \mathrm{~m}$ ). The largest departure between in-situ and ALS300 retrievals occurred on the 11th of June at 11:15 UTC with a value of $421.5 \mathrm{~m}$ (SML and DRCL at $1585 \mathrm{~m}$ and $1660 \mathrm{~m}$ ). On that day, the DRLC depth was only $75 \mathrm{~m}$, that is, only 5 percent of the depth on the 13th of June at 06:05 UTC. This supports the observation that shallower DRCL causes more uncertain retrievals of the BL.

6.2.2. CHM15K versus RS. Figure 7 shows the CHM15K-RS linear correlation at the SML and DRCL levels. Both layers show good correspondence with the RS-detected SML and DRCL supporting the decoupled structure of the BL from the temperature profile. The CHM15K-RS comparison counts, out of 23, 17 samples for the SML and 15 for the DRCL. The data summarized in Table 3 report the values of $R$, bias, and sigma $(0.88,177.2 \mathrm{~m}$, and $191.6 \mathrm{~m}$, resp. $)$ and the percentage of consistent retrievals in the comparison, $64.7 \%$. 
TABLE 3: Mean statistical parameters of the ALS300-CHM15K-CL31 versus radiosounding (RS) comparison. For each $X$ versus $Y$ comparison, $R$ is the correlation coefficient, bias = abs $(Y-X)$, Sigma $=$ std $(Y-X)$, and consistency is percentage of $X$ versus $Y$ detections closer than $200 \mathrm{~m}$, that is, abs $(Y-X) \leq 200 \mathrm{~m}$.

\begin{tabular}{|c|c|c|c|c|c|}
\hline Comparison (SML) & $R$ & Bias (m a.g.l.) & Sigma (m a.g.l.) & Consistency (\%) & Num. of samples \\
\hline ALS300 versus RS & 0.91 & 150.6 & 175.1 & 75.0 & 16 \\
\hline CL31 versus RS & 0.74 & 218.2 & 233.4 & 36.4 & 11 \\
\hline CHM15K versus RS & 0.88 & 177.2 & 191.6 & 64.7 & 17 \\
\hline Comparison (DRCL) & $R$ & Bias (m a.g.l.) & Sigma (m a.g.l.) & Consistency & \\
\hline ALS300 versus RS & 0.92 & 148.5 & 207.3 & 61.5 & 13 \\
\hline CL31 versus RS & 0.61 & 143.4 & 142.9 & 62.5 & 8 \\
\hline CHM15K versus RS & 0.81 & 192.1 & 235.8 & 53.3 & 15 \\
\hline
\end{tabular}

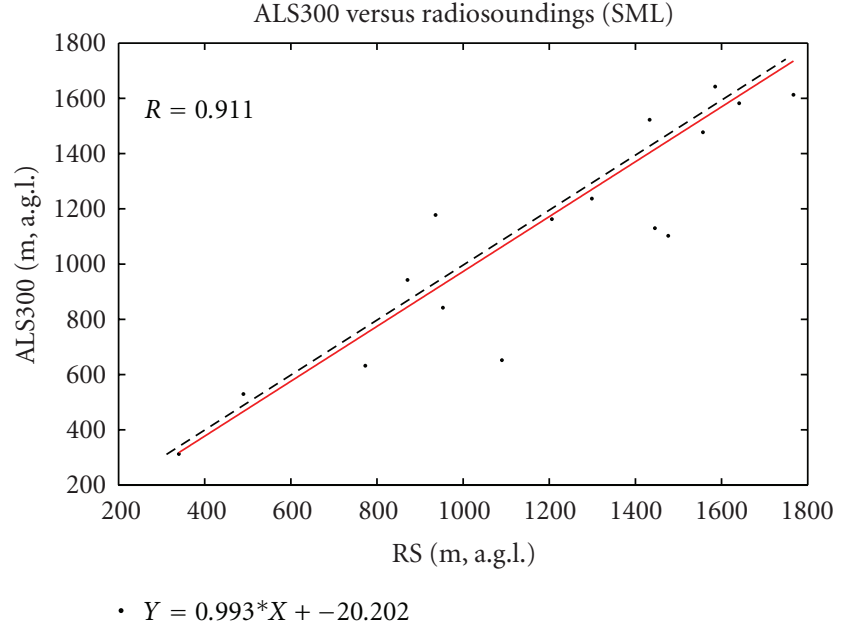

(a)

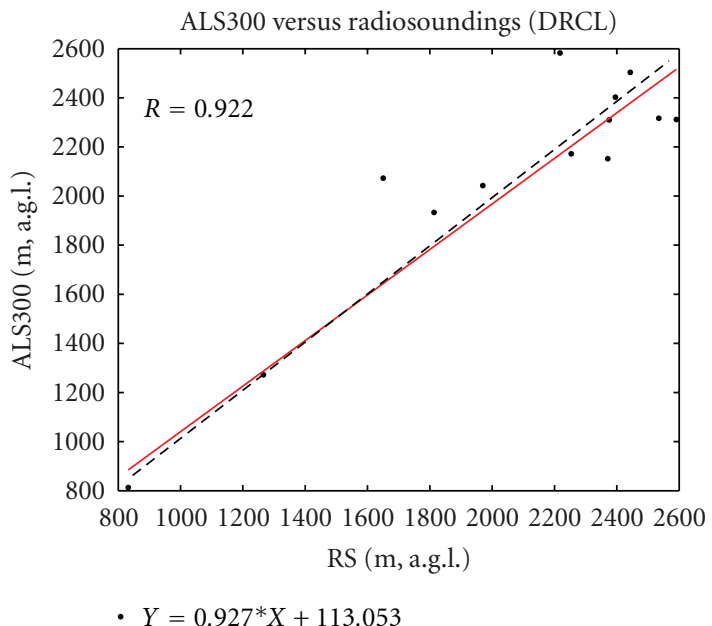

(b)

FIGURE 6: ALS300-RS comparison and linear correlation for SML and DRCL heights.

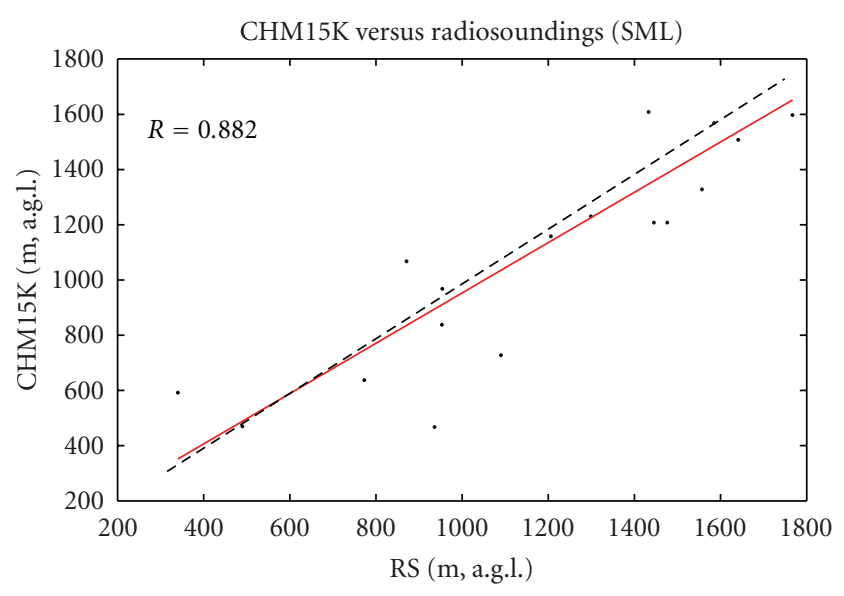

- $Y=0.911^{*} X+42.093$

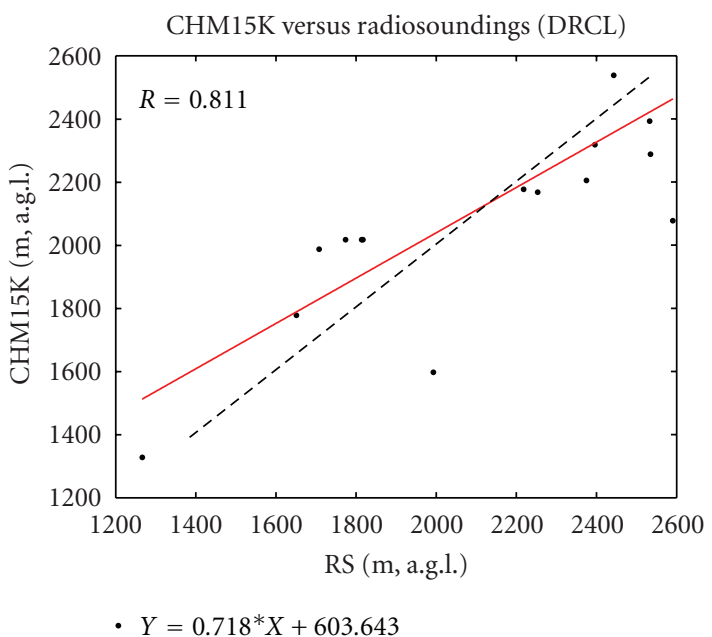

(b)

FIGURE 7: CHMK15K-RS comparison and linear correlation for SML and DRCL heights. 


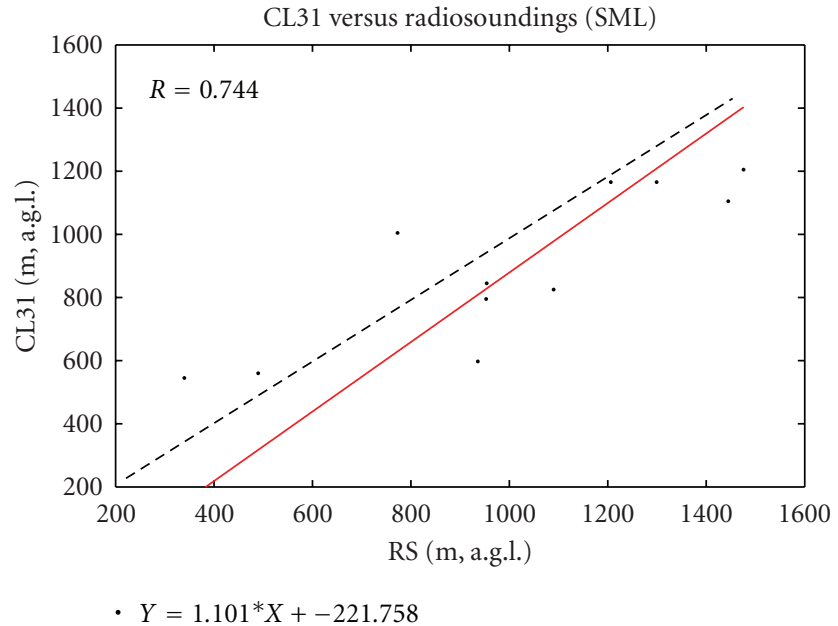

(a)

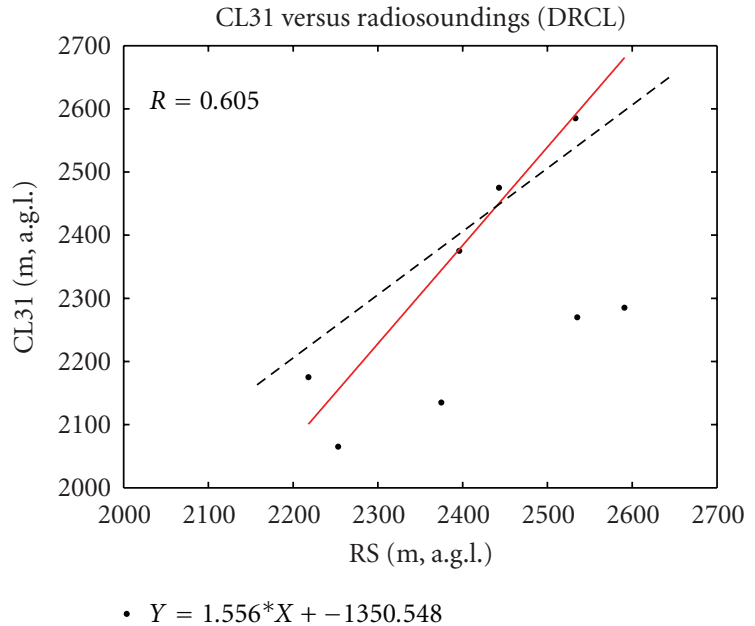

(b)

FIGURE 8: CL31-RS comparison and linear correlation for SML and DRCL heights.

Indications on the underestimation of the SML height by the CHM15K are provided by the slope of the linear fit (0.91) combined with the small intercept $(42 \mathrm{~m})$. The most consistent CHM15K-RS retrieval of the SML was $13 \mathrm{~m}$ and occurred on the 12th of June at 17:15 UTC (SML and DRCL at $954 \mathrm{~m}$ and $2260 \mathrm{~m}$ ). Although the rather complex meteorological conditions occurred through the day, the SML retrievals on the 12 th of June showed small CHM15KRS differences. Analyzing the reflectivity profiles from the colocated cloud radar it appears clearly that the two-layer cloud system which formed above Mace Head at 06:00 UTC and lasted until the end of the day corresponded to the two main temperature inversions in the RS profiles. Then, the very large echo from the lower and upper cloud bases in the lidar and ceilometers profiles matched consistently the RS-detected SML and DRCL (also see Figures 10 and 11). On the other hand, the less consistent CHM15K-RS retrieval of the SML was $270 \mathrm{~m}$ and occurred on the 13th of June at 17:35 UTC (SML and DRCL at $1445 \mathrm{~m}$ and $2560 \mathrm{~m}$ ). The CHM15K retrievals throughout the entire day largely differed from the RS retrievals. This was due to through-day persistent convective conditions, leading to high-frequency fluctuations of the SML. For what it concerns the upper layer, the average RS-detected DRCL depth over all cases was $800 \mathrm{~m}$, with the most consistent CHM15K-RS retrieval of 40.5 meters, and occurred on the 14th of June at 11:00 UTC (SML and DRCL at $953 \mathrm{~m}$ and $2224 \mathrm{~m}$ ). The remote and in-situ measurements on the 14th returned consistent DRCL values for the other three ascents too. For the 11:00 UTC ascent the RS-detected DRCL depth was $1271 \mathrm{~m}$, a considerably large convective layer which corresponded to well-defined temperature inversions.

The less consistent CHM15K-RS retrieval of the DRCL was $279.5 \mathrm{~m}$ and occurred on the 10th of June at 23:15 UTC (SML and DRCL at $1641 \mathrm{~m}$ and $1720 \mathrm{~m}$ ). The comparisons throughout the entire day showed larger differences compared to other cases. The 10th and the 11th of June had generally shallower DRCL, for example, only $79 \mathrm{~m}$ on the 10th at 23:15 UTC. The very thin DRCL (only 4 points in the CHM15K profile) corresponded to a less defined decoupling in the temperature profile as well, confirming that the comparison between the CHM15K and the RS improves when the temperature inversions are stronger and the two-layer BL structure is neatly decoupled.

6.2.3. CL31 versus RS. Figure 8 shows the CL31-RS linear correlations at the SML and DRCL levels. The correlation coefficient $R$ was 0.744 and 0.605 at the SML and DRCL, respectively. As expected and due to the rapidly decreasing SNR for $z>1 \mathrm{~km}$ especially in daylight, the comparison had higher $R$ at the SML. The CL31-RS comparison counts 11 samples at the SML and only 8 at the DRCL. The limited number of DRCL samples is indeed related to the worse daytime SNR compared to the CHM15K and the ALS300. Three days (12 data points) were not available for the comparison: on the 10th and 11th data were not available for technical reasons and on the 14th of June the CL31 did not detect the DRCL at the time of the four RS ascents. Nevertheless, data from Table 3 highlight that more DRCL than SML retrievals are consistent with the RS. In spite of a lower SNR, the bias is $218.2 \mathrm{~m}$ for the SML and $143.4 \mathrm{~m}$ for the DRCL leading to a consistency of $36.4 \%$ at the SML and as high as $62.5 \%$ at the DRCL level (an interpretation of this result is provided in Section 7).

The most consistent CL31-RS retrieval of the SML was $50 \mathrm{~m}$ and occurred on the 12th of June at 17:15 UTC (SML and DRCL at $954 \mathrm{~m}$ and $2253 \mathrm{~m}$ ). The less consistent CL31RS retrieval of the SML was $338.5 \mathrm{~m}$ and occurred, as for the CHM15K, on the 13th of June at 06:05 UTC (SML and DRCL at $936 \mathrm{~m}$ and $2420 \mathrm{~m}$ ). Throughout the entire day, the CL31-RS comparison showed significant departures. As for the previous comparison, the large discrepancies between remote and in-situ detections likely depended on 
the persisting convective conditions occurring during the central hours of the day.

For what it concerns the upper layer, the most consistent CL31-RS retrieval of the DRCL was $21 \mathrm{~m}$ and occurred on the 13th of June at 06:05 UTC with all DRCL. Contrarily from the SML, all CL31 retrievals of the DRCL during the 13th of June happened to be very consistent with the RS temperature inversions. The less consistent CL31-RS retrieval of the DRCL was $350 \mathrm{~m}$ and occurred on the 12th of June at 23:15 UTC (SML and DRCL at $1250 \mathrm{~m}$ and $2600 \mathrm{~m}$ ).

6.3. Remote-to-In Situ Comparison on the 9th and 12th of June 2009. The case of 9th of June is analysed and shown in Figure 9 outlining the ALS300 and CL31 comparisons with the RS. Solid and dashed horizontal lines in the bottom panel of Figure 9 show the altitude of the two RS-detected temperature inversions. On the 9th of June at 05:15 UTC (sunrise at 04:12 UTC) the CL31 and the ALS300 clearly detected the top of the local DRCL in correspondence of a capping stratus cloud at $1670 \mathrm{~m}$ and $1500 \mathrm{~m}$, respectively. No decoupled structure was observed at the time of the observations which suggests that aerosols may still have been distributed homogeneously along the BL despite an already formed temperature inversion. In fact, the RS showed a clear low-level inversion at $315 \mathrm{~m}$ corresponding to the SML and a second inversion further up at $1720 \mathrm{~m}$ matching the ALS300- and CL31-retrieved DRCL. As mentioned in Section 1, the boundary layer is defined as the top of the atmospheric region where friction and convection generated at the surface influences directly the turbulent mixing which determines the homogeneous distribution of the aerosols. Based on this definition and assuming that convection and turbulent mixing determine the height of the first temperature inversion, the level where the aerosol concentration abruptly decreases should match the level of the first temperature inversion. The fact that this did not happen on the morning of the 9th of June can be explained by the meteorological conditions and BL dynamics present at the time. However the sunrise occurred one hour before the RS ascent, and the sky remained cloudy preventing the sun to start the convective mixing of aerosols. A delay between the rise of the temperature inversion and the formation of the SML is then likely to have occurred.

Conversely, the case shown in Figure 10 is an example of good matching of the detected BL structure by remote and in-situ measurements. On the 12th of June 2009 a two-layer stratiform cloud capped the BL above Mace Head at 11:15 UTC; the atmospheric region below the higher cloud base appeared to be well mixed, as it demonstrates the almost adiabatic temperature profiles in the bottom-left panel of Figure 10. From the RS retrievals we can see a large inversion at $1210 \mathrm{~m}$ and another inversion at $510 \mathrm{~m}$ : the bottom-right panel shows that the peak in the gradient at $510 \mathrm{~m}$ is much less pronounced than the upper inversion at $1210 \mathrm{~m}$, showing that despite the presence of the cloud at $\sim 500 \mathrm{~m}$, this did not influence significantly the temperature mixing in the BL. Differently from the previous case, the lidar and the two ceilometers data were all available on the 12th. Figure 11 shows the height range $400 \mathrm{~m}$ to $600 \mathrm{~m}$ for the three sensors showing the backscatter profiles at 11:15 UTC. The three sensors show homogeneous, well-mixed layer below the upper cloud base with very weak decoupling at the heights $530 \mathrm{~m}, 510 \mathrm{~m}$, and $560 \mathrm{~m}$ for ALS300, CHM15K, and CL31, respectively.

\section{Conclusions}

This study is a two-step investigation of the BL structure over Mace Head, Ireland, in the framework of the ICOS field campaign from the 8th to the 28th of June 2009. The two steps are (i) the intercomparison of three lidar-based sensors and (ii) the comparison of the backscatter profiles with the radiosounding-retrieved temperature profiles. For the first part of the study, three laser sensors have been intercompared, an elastic backscatter lidar (Leosphere ALS300) and two ceilometers (Jenoptik CHM15K and Vaisala CL31). The Temporal Height-Tracking algorithm $[4,26,27]$ has been applied to the backscatter profiles of the three sensors to retrieve the structure of the BL. The description of the BL by the THT is based on a two-layer BL with a surface mixed layer and a decoupled residual (nocturnal) or convective (diurnal) layer retrieved. The 21 timeseries (daily comparisons from the 8th to the 28th of June, 2009) of SML and DRCL heights obtained from the three sensors' backscatter profiles have been intercompared and summarized in Table 1. The intercomparison showed more consistent retrievals for the ALS300-CHM15K comparison at both the SML and DRCL with, respectively, the $86.5 \%$ and $77.2 \%$ consistency. In general the consistency amongst the three sensors was higher at the SML than at the DRCL. This last result can be interpreted by considering the different SNR of the three sensors: at the SML and DRCL levels the SNR for the ceilometers depends on a number of factors including aerosol load, BL height, meteorological conditions, and time of day. Similarly, lidars depend on the same factors, but because they can rely on larger laser power and, generally, on better receiver efficiency the SNR, at higher ranges (DRCL), becomes larger with respect to the ceilometers [30]. The different profile of SNR of the three sensors determines low $R$ at the DRCL. Moreover, the larger power of the ALS300 and CHM15K determines better skill to penetrate optically thin clouds and to retrieve aerosol layers above it. On the other hand, when multiple aerosol layers are present within the SML and the DRCL, the ALS300-RS comparison may prove to be complicated because of the large sensitivity to fine aerosol layers (large gradient) in the ALS300 backscatter profile. As general outcome of the intercomparison the mean correlation coefficients over all the collected cases were $R=$ $0.88,0.82$, and 0.76 for ALS300 versus CHM15K, CHM15K versus CL31, and ALS300 versus CL31, respectively.

The second part of the study also highlights the dynamics leading to low values of $R$ : (i) enhanced convection resulting in high-frequency variations of the SML and DRCL heights, (ii) shallow DRCL, and (iii) weak temperature inversions. Temporal and vertical resolutions of lidar and ceilometers are, along with the SNR, key parameters that determine the 
9th of June, 2009
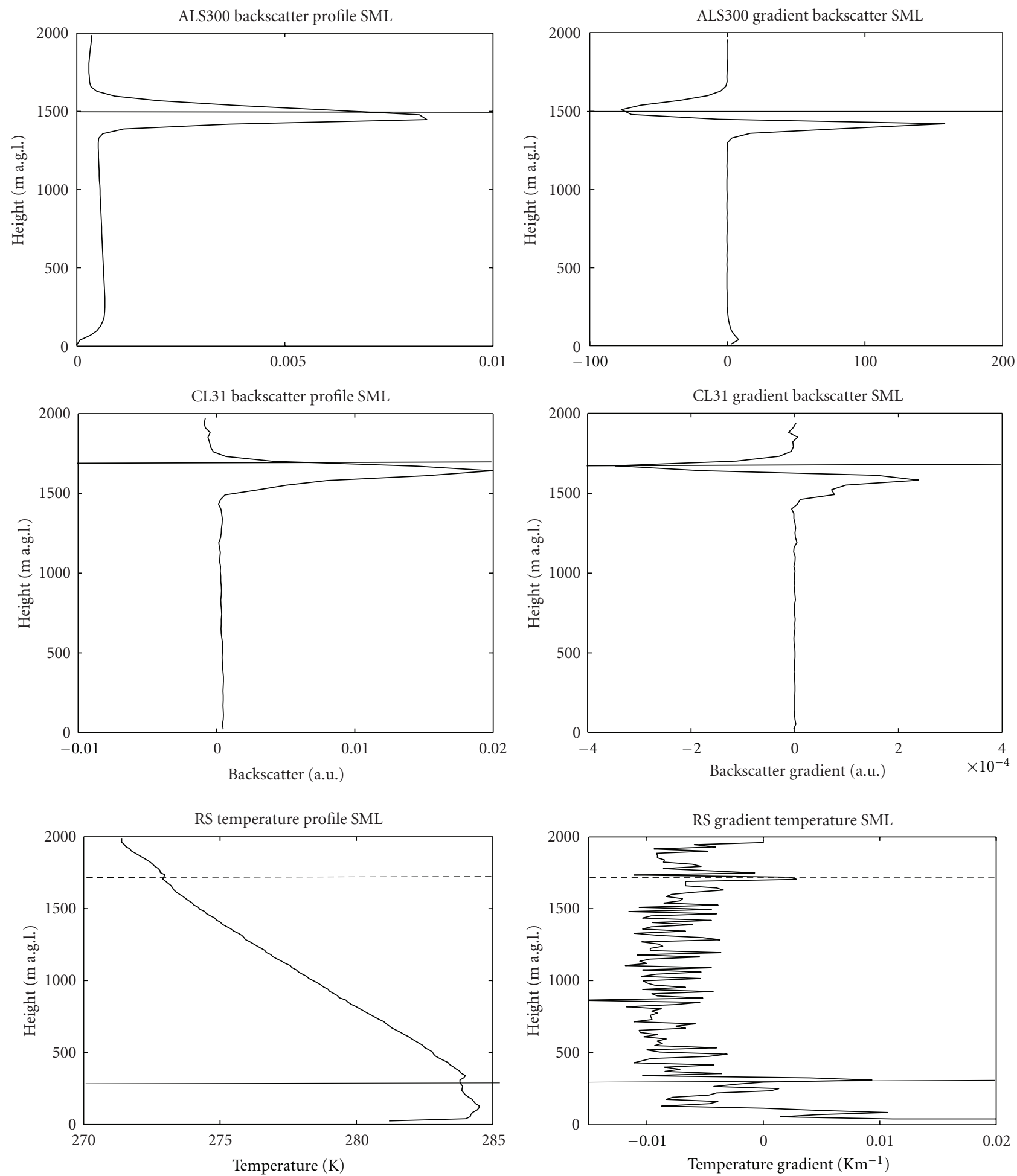

FiguRE 9: CL31-RS and ALS300-RS on 9 June 2009, 0515 UTC. Top and middle left, 10-minute averaged backscatter profile; top and middle right, log gradient of backscatter profiles; bottom left, temperature profile; bottom right, vertical gradient of temperature profile. Horizontal dashed and solid lines represent DRCL and SML detection, respectively. 
12th of June, 2009
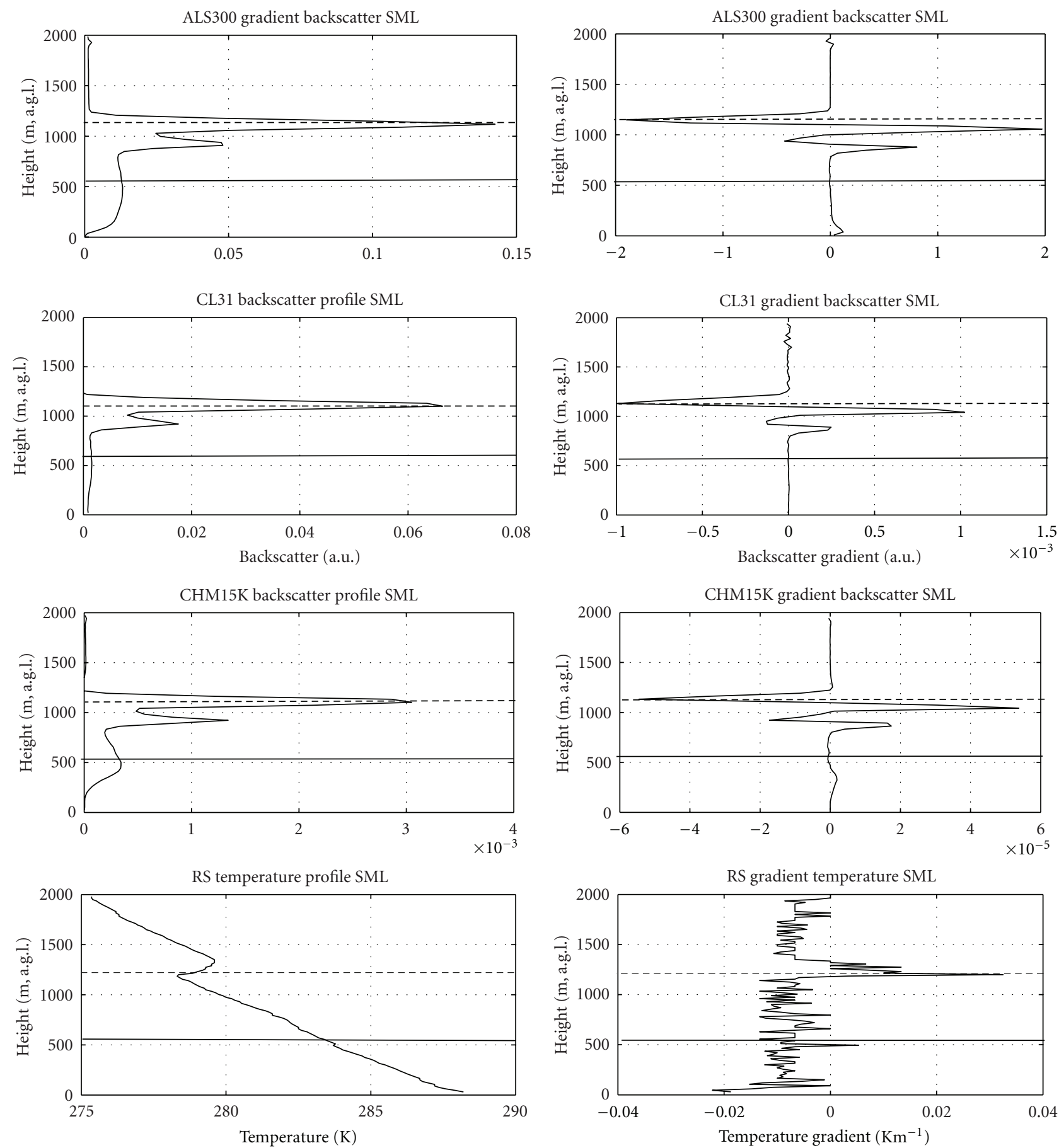

Figure 10: CL31-RS and ALS300-RS on 12 June 2009, 1115 UTC. Top and middle left, 10-minute averaged backscatter profile; top and middle right, log gradient of backscatter profiles; bottom left, temperature profile; bottom right, vertical gradient of temperature profile. Horizontal dashed and solid lines represent DRCL and SML detection, respectively.

accuracy of the retrievals. The observations from both the RS and the laser sensors demonstrate that the SML and the DRCL characterize the decoupled structure of the $\mathrm{BL}$ above Mace Head. Remote-to-in situ correlations for cases where the temperature inversion is well defined are in general high. The $R$ values for the remote-to-in situ comparisons at the SML were $0.91,0.74$ and 0.88 for the ALS300, CL31 and CHM15K, respectively. Similarly, the value of $R$ for the DRCL comparisons was $0.92,0.61$, and 0.81 for the ALS300, CL31, and CHM15K, respectively. Table 3 shows that the 

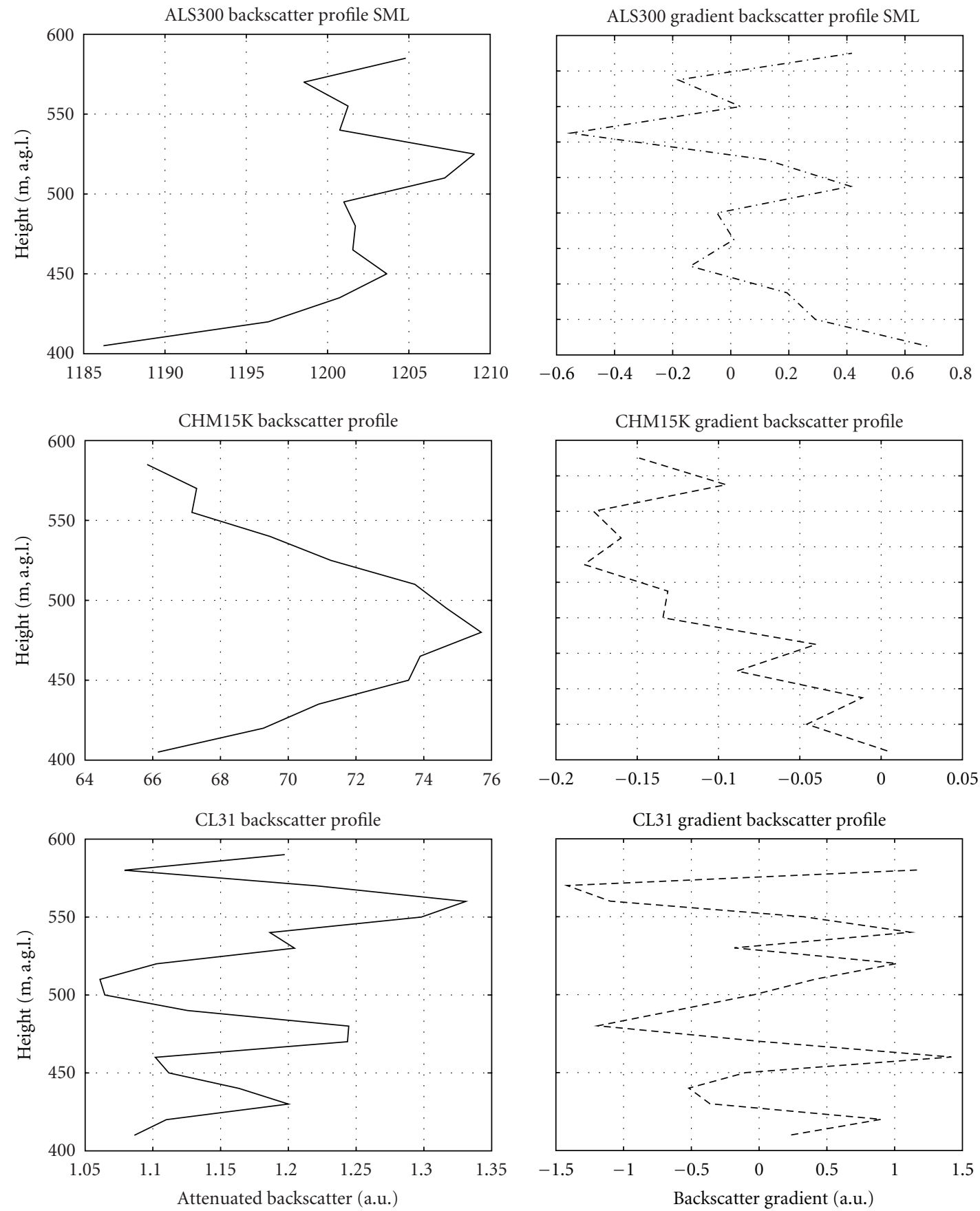

Figure 11: $400 \mathrm{~m}$ to $600 \mathrm{~m}$ height section of ALS300, CL31 and CHM15K's 10 minute average of backscatter (left hand side panel) and gradient backscatter (right hand side panel) for the 12th of Jun 2009, 11:15 UTC.

most consistent retrievals at the SML level are those from the ALS300 with $75 \%$ of the detections closer than $200 \mathrm{~m}$ to the RS's first temperature inversion. Despite the lower SNR and $R$-value compared to the ASL300 and CHM15K, the CL31 retrieves the DRCL more consistently with respect to the RS with $62.5 \%$ of detections closer than $200 \mathrm{~m}$ to the second temperature inversion. However, the number of samples of the CL31-RS comparison is only $\sim 60 \%$ of the CHM15K-RS and ALS300-RS. This means that only in 5 cases out 23 the
CL31 is getting DRCL detections closer than $200 \mathrm{~m}$ to the RS's. Finally, the results reported in Table 3 show that most of the remote sensing retrievals are consistent $(200 \mathrm{~m})$ with the radiosoundings temperature gradients, confirming the results of other recent studies $[4,25,41]$.

Finally, this study shows that meteorological conditions significantly affect the results of the comparisons; clear sky conditions reduce the attenuation of the signal thus improving the instruments comparison. Strongly attenuated 
signals due to precipitation, clouds, and fog must be discarded as unreliable. Stable (e.g., nocturnal) conditions cause aerosols stratification along the column determining higher number of aerosol layers increasing the uncertainty when locating the SML and DRCL using different instruments. Results improved by increasing the time averaging over the backscatter profiles; 5 - to 10-minute intervals reduced the divergence between different instruments' detections.

\section{Acronyms}

PBL: Planetary boundary layer

BL: Boundary layer

SML: Surface mixed layer

DRCL: Decoupled residual or convective layer

FOV: Field of view

GS: Gradient signal

RCS: Range-corrected signal

SNR: Signal-to-noise ratio

UTC: Universal time coordinated.

\section{Acknowledgments}

The authors acknowledge the ICOS Preparatory Phase project for funding the radiosoundings. They are grateful to Jenny Hanafin, Cyrille Vuillemin, Benoit Wastine, and Guillaime Gorju for their important contribution in carrying out the radiosoundings and helping to set up optimally the instrumentation deployed during the field campaign.

\section{References}

[1] J. M. White, J. F. Bowers, S. R. Hanna, and J. K. Lundquist, "Importance of using observations of mixing depths in order to avoid large prediction errors by a transport and dispersion model," Journal of Atmospheric and Oceanic Technology, vol. 26, no. 1, pp. 22-32, 2009.

[2] G. J. Kunz, G. De Leeuw, E. Becker, and C. D. O’Dowd, "Lidar observations of atmospheric boundary layer structure and sea spray aerosol plumes generation and transport at Mace Head, Ireland (PARFORCE experiment)," Journal of Geophysical Research D, vol. 107, no. 19, article 8106, 2002.

[3] S. Serafin and D. Zardi, "Structure of the atmospheric boundary layer in the vicinity of a developing upslope flow system: a numerical model study," Journal of the Atmospheric Sciences, vol. 67, no. 4, pp. 1171-1185, 2010.

[4] M. Haeffelin, F. Angelini, Y. Morille et al., "Evaluation of Mixing-Height Retrievals from Automatic Profiling Lidars and Ceilometers in View of Future Integrated Networks in Europe," Boundary-Layer Meteorology, vol. 143, no. 1, pp. 4975, 2012.

[5] A. Colette, L. Menut, M. Haeffelin, and Y. Morille, "Impact of the transport of aerosols from the free troposphere towards the boundary layer on the air quality in the Paris area," Atmospheric Environment, vol. 42, no. 2, pp. 390-402, 2008.

[6] C. Flamant, P. Knippertz, D. J. Parker et al., "The impact of a mesoscale convective system cold pool on the northward propagation of the intertropical discontinuity over West Africa," Quarterly Journal of the Royal Meteorological Society, vol. 135, no. 638, pp. 139-159, 2009.
[7] D. B. Karam, C. Flamant, P. Tulet, M. C. Todd, J. Pelon, and E. Williams, "Dry cyclogenesis and dust mobilization in the intertropical discontinuity of the West African Monsoon: a case study," Journal of Geophysical Research D, vol. 114, no. 5, Article ID D05115, 2009.

[8] H. Flentje, H. Claude, T. Elste et al., "The Eyjafjallajökull eruption in April 2010 — detection of volcanic plume using in-situ measurements, ozone sondes and lidar-ceilometer profiles," Atmospheric Chemistry and Physics, vol. 10, no. 20, pp. 10085-10092, 2010.

[9] C. D. O’Dowd, D. Ceburnis, J. Ovadnevaite et al., "The eyjafjallajökull ash plume e-part I: physical, chemical and optical characteristics," Atmospheric Environment, vol. 48, pp. 129-142, 2012.

[10] C. D. O’Dowd, S. Varghese, R. Flanagan et al., "The eyjafjallajökull ash plume-part 2: forecasting ash cloud dispersion," Atmospheric Environment, vol. 48, pp. 143-151, 2012.

[11] I. Salma, I. Balásházy, R. Winkler-Heil, W. Hofmann, and G. Záray, "Effect of particle mass size distribution on the deposition of aerosols in the human respiratory system," Journal of Aerosol Science, vol. 33, no. 1, pp. 119-132, 2002.

[12] J. M. Hales, L. C. Schwendiman, and T. W. Horst, "Aerosol transport in a naturally-convected boundary layer," International Journal of Heat and Mass Transfer, vol. 15, no. 10, pp. 1837-1850, 1972.

[13] A. F. Mills and A. T. Wassel, "Aerosol transport in a thermally driven natural convection boundary layer," Letters in Heat and Mass Transfer, vol. 2, no. 2, pp. 159-167, 1975.

[14] M. Dall'Osto, D. Ceburnis, G. Martucci et al., "Aerosol properties associated with air masses arriving into the North East Atlantic during the 2008 Mace Head EUCAARI intensive observing period: An overview," Atmospheric Chemistry and Physics, vol. 10, pp. 8413-8435, 2010.

[15] R. G. Derwent, P. G. Simmonds, and W. J. Collins, "Ozone and carbon monoxide measurements at a remote maritime location, Mace Head, Ireland, from 1990 to 1992," Atmospheric Environment, vol. 28, no. 16, pp. 2623-2637, 1994.

[16] F. M. McGovern, A. Krasenbrink, S. G. Jennings et al., "Mass measurements of aerosol at Mace Head, on the west coast of Ireland," Atmospheric Environment, vol. 28, no. 7, pp. 13111318, 1994.

[17] S. Huang, R. Arimoto, and K. A. Rahn, "Sources and source variations for aerosol at Mace Head, Ireland," Atmospheric Environment, vol. 35, no. 8, pp. 1421-1437, 2001.

[18] R. Boers, H. Russchenberg, J. Erkelens et al., "Ground-based remote sensing of stratocumulus properties during CLARA, 1996," Journal of Applied Meteorology, vol. 39, no. 2, pp. 169$181,2000$.

[19] E. E. Clothiaux, T. P. Ackerman, G. G. Mace et al., "Objective determination of cloud heights and radar reflectivities using a combination of active remote sensors at the ARM CART sites," Journal of Applied Meteorology, vol. 39, no. 5, pp. 645-665, 2000.

[20] C. P. Kalb, A. R. Dean, R. A. Peppler, and K. L. Sonntag, "Intercomparison of cloud base height at the ARM Southern Great plains site," in Proceedings of the 14th Atmospheric Radiation Measurement (ARM '04), U.S. Department of Energy, Albuquerque, NM, USA, 2004.

[21] M. Sicard, C. Pérez, F. Rocadenbosch, J. M. Baldasano, and D. García-Vizcaino, "Mixed layer depth determination in the Barcelona costal area from regular lidar measurements: methods, results and limitations," Boundary-Layer Meteorology, vol. 119, no. 1, pp. 135-157, 2006. 
[22] O. P. Cramer, "Potential temperature analysis for mountainous terrain," Journal of Applied Meteorology, vol. 11, pp. 44-50, 1972.

[23] W. A. J. Van Pul, A. A. M. Holtslag, and D. P. J. Swart, "A comparison of $\mathrm{ABL}$ heights inferred routinely from lidar and radiosondes at noontime," Boundary-Layer Meteorology, vol. 68, no. 1-2, pp. 173-191, 1994.

[24] S. F. J. De Wekker, M. Kossmann, and F. Fielder, "Observations of daytime mixed layer heights over mountainous terrain during the TRACT field campaign," in Proceedings of the 12th Symposium on Boundary Layers and Turbulence, pp. 498-499, American Meteorological Society, Vancouver, BC, Canada, 1997.

[25] G. Martucci, R. Matthey, V. Mitev, and H. Richner, "Comparison between backscatter lidar and radiosonde measurements of the diurnal and nocturnal stratification in the lower troposphere," Journal of Atmospheric and Oceanic Technology, vol. 24, no. 7, pp. 1231-1244, 2007.

[26] G. Martucci, C. Milroy, and C. D. O’Dowd, "Detection of cloud-base height using Jenoptik CHM15K and Vaisala CL31 ceilometers," Journal of Atmospheric and Oceanic Technology, vol. 27, no. 2, pp. 305-318, 2010.

[27] G. Martucci, R. Matthey, V. Mitev, and H. Richner, "Frequency of boundary-layer-top fluctuations in convective and stable conditions using laser remote sensing," Boundary-Layer Meteorology, vol. 135, no. 2, pp. 313-331, 2010.

[28] J. D. Klett, "Stable analytical inversion solution for processing lidar returns," Applied Optics, vol. 20, no. 2, pp. 211-220, 1981.

[29] H. Flentje, B. Heese, J. Reichardt, and W. Thomas, "Aerosol profiling using the ceilometer 10 network of the German meteorological service," Atmospheric Measurement Techniques, vol. 3, pp. 3643-3673, 2010.

[30] B. Heese, H. Flentje, D. Althausen, A. Ansmann, and S. Frey, "Ceilometer lidar comparison: backscatter coefficient retrieval and signal-to-noise ratio determination," Atmospheric Measurement Techniques, vol. 3, pp. 1763-1770, 2010.

[31] C. Münkel, N. Eresmaa, J. Räsänen, and A. Karppinen, "Retrieval of mixing height and dust concentration with lidar ceilometer," Boundary-Layer Meteorology, vol. 124, no. 1, pp. 117-128, 2007.

[32] R. B. Stull, An Introduction to Boundary-Layer Meteorology, Kluwer Academic Publishers, Dordrecht, The Netherlands, 1988.

[33] G. Martucci and C. D. O’Dowd, "ICOS field campaign at mace head," Tech. Rep., Ireland, 2009.

[34] C. Weitkamp, "Lidar: range-resolved optical remote sensing of the atmosphere," Springer Series of Optical Sciences, vol. 102, p. 460, 2005.

[35] C. Flamant, J. Pelon, P. H. Flamant, and P. Durand, "Lidar determination of the entrainment zone thickness at the top of the unstable marine atmospheric boundary layer," BoundaryLayer Meteorology, vol. 83, no. 2, pp. 247-284, 1997.

[36] L. Menut, C. Flamant, J. Pelon, and P. H. Flamant, "Urban boundary-layer height determination from lidar measurements over the Paris area," Applied Optics, vol. 38, no. 6, pp. 945-954, 1999.

[37] B. Hennemuth and A. Lammert, "Determination of the atmospheric boundary layer height from radiosonde and lidar backscatter," Boundary-Layer Meteorology, vol. 120, no. 1, pp. 181-200, 2006.

[38] W. P. Hooper and E. W. Eloranta, "Lidar measurements of wind in the planetary boundary layer: the method, accuracy and results from joint measurements with radiosonde and kytoon.," Journal of Climate \& Applied Meteorology, vol. 25, no. 7, pp. 990-1001, 1986.

[39] D. G. Steyn, M. Baldi, and R. M. Hoff, "The detection of mixed layer depth and entrainment zone thickness from lidar backscatter profiles," Journal of Atmospheric and Oceanic Technology, vol. 16, no. 7, pp. 953-959, 1999.

[40] N. Eresmaa, A. Karppinen, S. M. Joffre, J. Räsänen, and H. Talvitie, "Mixing height determination by ceilometer," Atmospheric Chemistry and Physics, vol. 6, no. 6, pp. 14851493, 2006.

[41] D. J. Seidel, C. O. Ao, and K. Li, "Estimating climatological planetary boundary layer heights from radiosonde observations: comparison of methods and uncertainty analysis," Journal of Geophysical Research D, vol. 115, no. 16, Article ID D16113, 2010. 

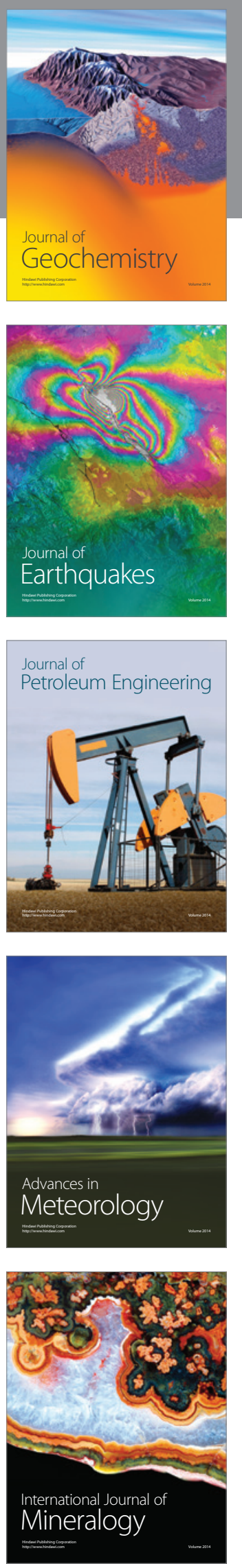
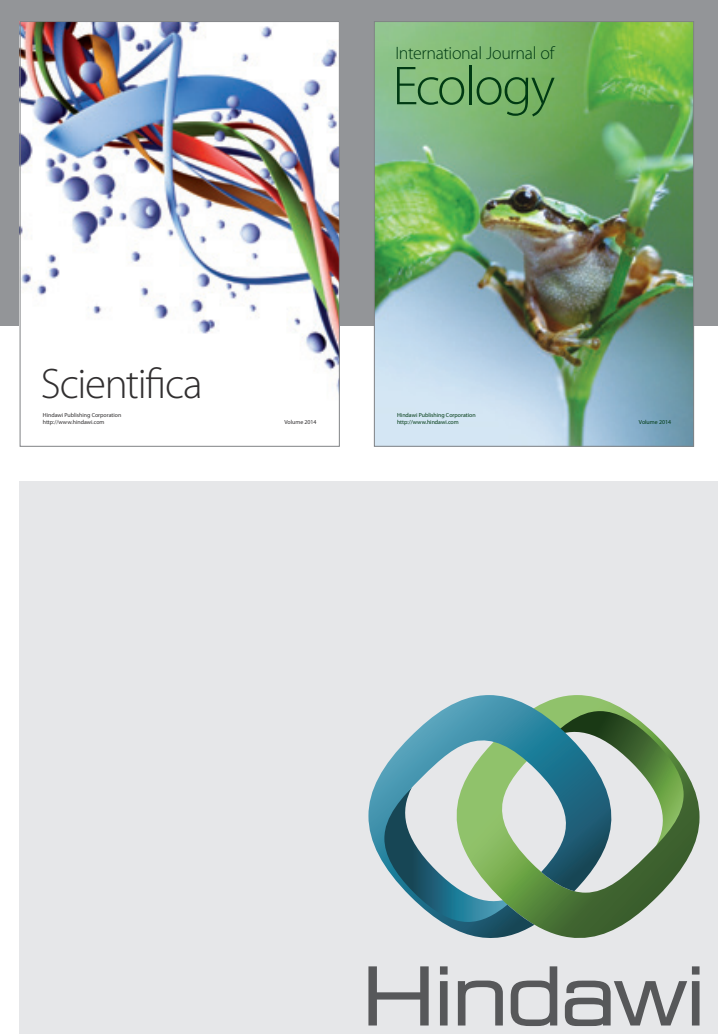

Submit your manuscripts at http://www.hindawi.com
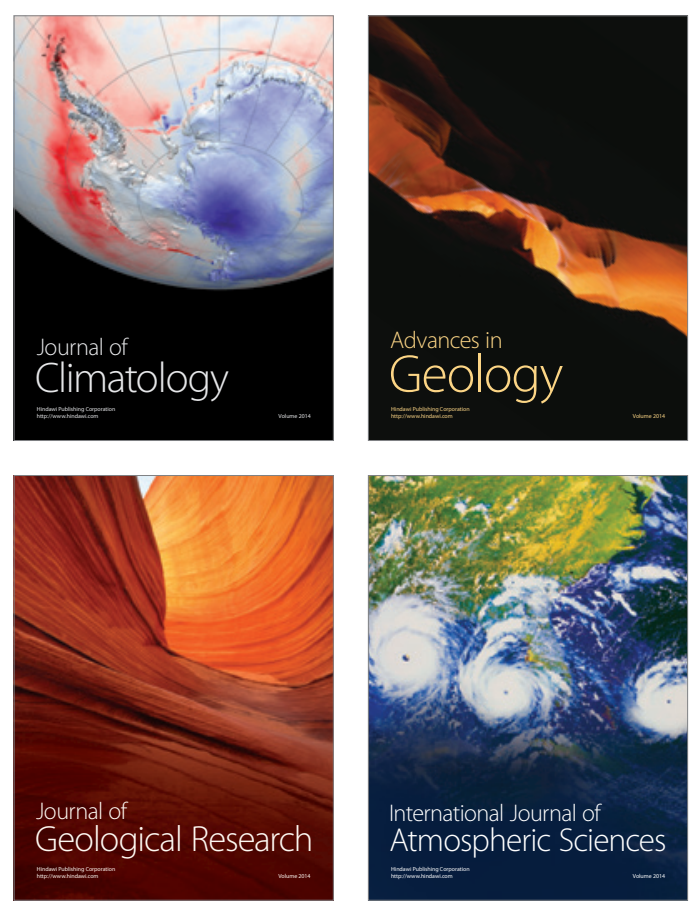
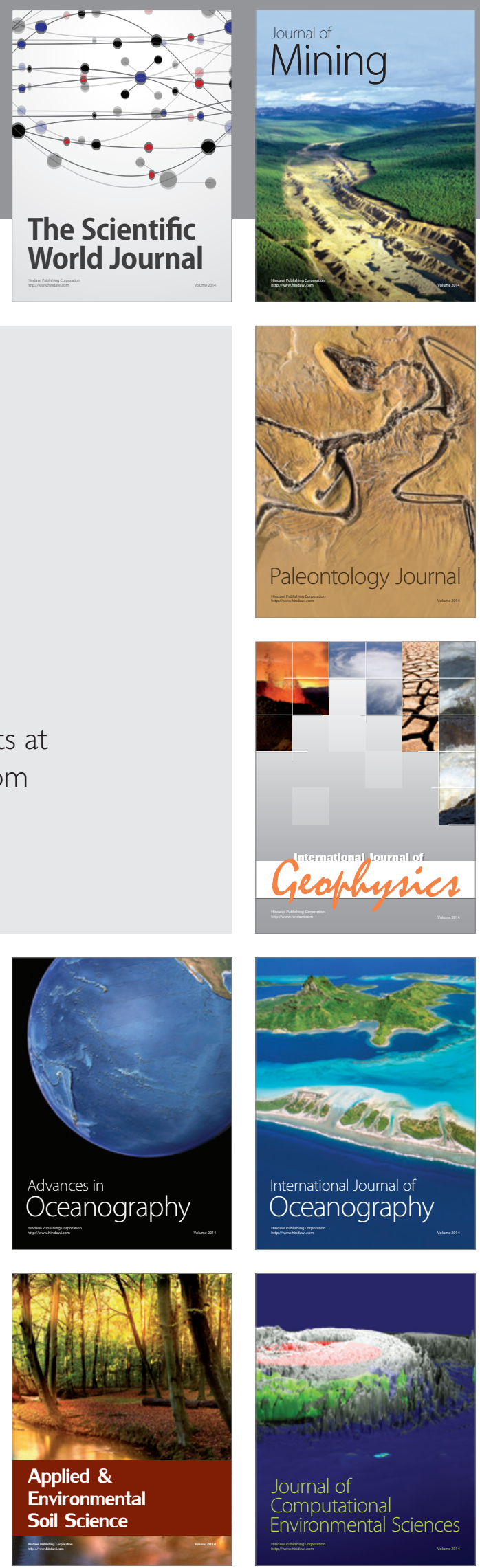